\title{
Sediment behavior controls equilibrium width of subglacial channels
}

\author{
ANDERS DAMSGAARD, ${ }^{1 *}$ JENNY SUCKALE, ${ }^{2,3}$ JAN A. PIOTROWSKI, ${ }^{4}$ \\ MORGANE HOUSSAIS, ${ }^{5}$ MATTHEW R. SIEGFRIED, ${ }^{1,2}$ HELEN A. FRICKER ${ }^{1}$ \\ ${ }^{1}$ Institute of Geophysics and Planetary Physics, Scripps Institution of Oceanography, University of California, San Diego, \\ CA, USA \\ ${ }^{2}$ Department of Geophysics, Stanford University, Stanford, CA, USA \\ ${ }^{3}$ Institute of Computational and Mathematical Engineering, Stanford University, Stanford, CA, USA \\ ${ }^{4}$ Department of Geoscience, Aarhus University, Aarhus, Denmark \\ ${ }^{5}$ Levich Institute, City College of CUNY, 140th Street and Convent Avenue, New York, NY, USA \\ Correspondence: Anders Damsgaard <andersd@princeton.edu>
}

\begin{abstract}
Flow-frictional resistance at the base of glaciers and ice sheets is strongly linked to subglacial water pressure. Understanding the physical mechanisms that govern meltwater fluxes in subglacial channels is hence critical for constraining variations in ice flow. Previous mathematical descriptions of softbed subglacial channels assume a viscous till rheology, which is inconsistent with laboratory data and the majority of field studies. Here, we use a grain-scale numerical formulation coupled to pore-water dynamics to analyze the structural stability of channels carved into soft beds. Contrary to the soft-bed channel models assuming viscous till rheology, we show that the flanks of till channels can support substantial ice loads without creep closure of the channel, because the sediment has finite frictional strength. Increased normal stress on the channel flanks causes plastic failure of the sediment, and the channel rapidly shrinks to increase the ice-bed contact area. We derive a new parameterization for subglacial channelized flow on soft beds and show that channel dynamics are dominated by fluvial erosion and deposition processes with thresholds linked to the plastic rheology of subglacial tills. We infer that the described limits to channel size may cause subglacial drainage to arrange in networks of multiple closely spaced channels.
\end{abstract}

KEYWORDS: glacier hydrology, glacial tills, subglacial processes, subglacial sediments

\section{INTRODUCTION}

Channelization of subglacial meltwater is well documented from the sedimentary and geomorphological record (e.g., Piotrowski, 1999; Piotrowski and others, 1999; Jørgensen and Sandersen, 2006; Greenwood and others, 2016; Bjarnadóttir and others, 2017; Simkins and others, 2017). Several geophysical investigations support that channelization of subglacial meltwater is an important process under contemporary glaciers and ice sheets (e.g., Hubbard and Nienow, 1997; Winberry and others, 2009; Horgan and others, 2013; Le Brocq and others, 2013; Schroeder and others, 2013; Gimbert and others, 2016; Drews and others, 2017). Numerical models of Antarctic ice-stream flow have shown that channelized water flow is necessary for producing sufficient variations in water pressure and subglacial friction, to match observed variations in ice-surface velocity (e.g., Thompson and others, 2014; Rosier and others, 2015), and meltwater channelization appears to be necessary for stabilizing ice-stream shear margins (Suckale and others, 2014; Perol and Rice, 2015; Perol and others, 2015; Elsworth and Suckale, 2016). Channelized meltwater flow is especially important for water and ice dynamics during subglacial lake drainage events (e.g., Bartholomew and others, 2010; Stevens and others, 2015; Brinkerhoff

* Present address: Geophysical Fluid Dynamics Laboratory, Princeton University, NJ, USA. and others, 2016; Dow and others, 2016; Fricker and others, 2016; Carter and others, 2017; Simkins and others, 2017). Recent studies have detailed that the influence of channel dynamics extends downstream of the grounding line, since point release of water through channels at grounding lines greatly enhances basal melt rates through the formation of turbulent buoyant plumes (e.g., Jenkins, 2011; Xu and others, 2012; Le Brocq and others, 2013; Marsh and others, 2016; Alley and others, 2016; Drews and others, 2017).

Channelization is not only relevant for projecting ice fluxes, but also for understanding subglacial landforms as water flow in the channels may be a primary mechanism for eroding and delivering sediment from the ice-sheet or glacier interior to its margin (e.g., Swift and others, 2002; Alley and others, 2003; Kehew and others, 2012; Bjarnadóttir and others, 2017). Recent discoveries of curvilinear and erosive landforms near the last-glacial maximum terminus (Fig. 1) have raised questions on how subglacial drainage systems arrange on soft beds (Lesemann and others, 2010, 2014).

Glacier beds provide resistive friction to glaciers and ice sheets and limit how fast they flow, and are typically subdivided into hard (rigid and impermeable) or soft (deformable and typically sedimentary) types. The amount of resistance provided by the bed is strongly dependent on subglacial water pressure (e.g., Weertman, 1957; Lliboutry, 1968; Budd and others, 1979; Iken, 1981; Bindschadler, 1983; 


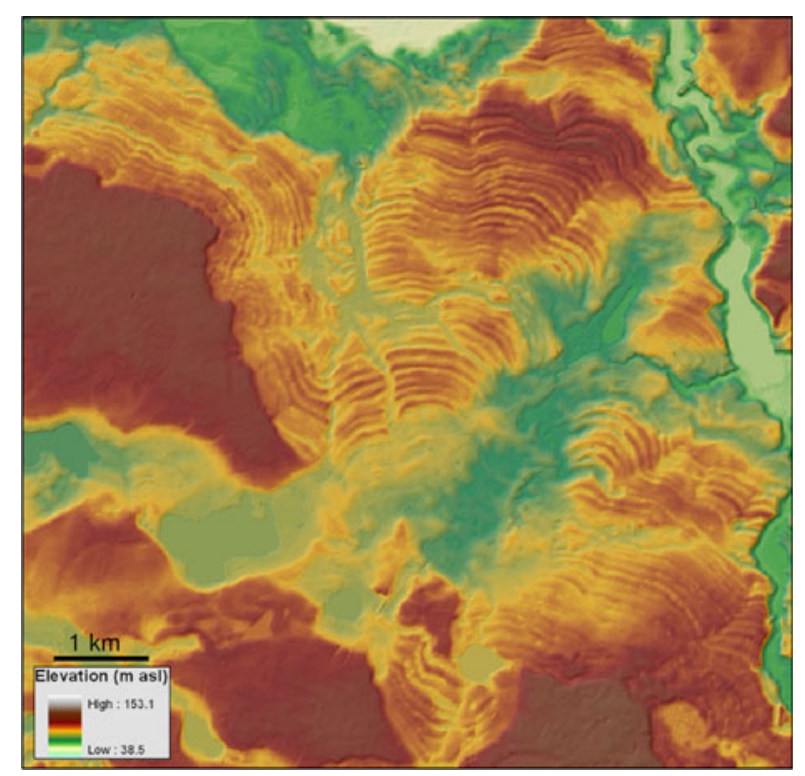

Fig. 1. Glacial curvilineations incised into sedimentary plateaus by subglacial meltwater erosion during the last glaciation near Zbójno, Poland, from Lesemann and others (2010). Water and ice-sheet flow was generally from the top left (NW) to the lower right (SE).

Boulton and Hindmarsh, 1987; Fowler, 1987; Kamb, 1991; Hooke and others, 1997), and subglacial channels are the most efficient drainage type and water-pressure altering component at the ice-bed interface (e.g., Flowers, 2015). Meltwater evacuation through channels generally decreases pore-water pressure and increases basal strength in the adjacent areas under the ice (e.g., Shoemaker, 1986; Boulton and Hindmarsh, 1987; Rempel, 2009). Since changes in subglacial water-flow patterns directly affect the glacier stress balance, changes in subglacial hydrology can cause largescale rearrangement in the flow patterns of ice sheets (e.g., Raymond, 2000; Tulaczyk and others, 2000a,b; Boulton and others, 2009; Piotrowski and others, 2009; Bougamont and others, 2015; Elsworth and Suckale, 2016).

The importance of changes in subglacial hydrology on ice flow has sparked efforts to develop and improve mathematical descriptions of subglacial water-pressure evolution in ice-flow models (e.g., Bougamont and others, 2011; van der Wel and others, 2013; Werder and others, 2013; de Fleurian and others, 2014; Kyrke-Smith and others, 2015). Building on the pioneering work of Röthlisberger (1972), Shreve (1972), and Nye (1976), which established the mathematical framework of dynamic water flow through channels melted into basal ice (R-channels), recent studies have improved our understanding of subglacial water drainage as a coupled system on hard beds. Differences in drainage properties between distributed and discrete drainage modes hint towards a complex interplay during non-steady drainage (e.g., Schoof, 2010; Hewitt, 2011, 2013; Kingslake and Ng, 2013; Werder and others, 2013). Schoof (2010) and Hewitt (2013) demonstrated that variability in meltwater input has the potential to cause ice-flow acceleration, because transient increases in meltwater supply overwhelm the watertransport capacity of the subglacial hydrological system. However, the majority of ice in contemporary and past ice sheets moves over soft beds (e.g., Alley and others, 1986; Engelhardt and others, 1990; Anandakrishnan and others, 1998; Tulaczyk and others, 2000a; Kamb, 2001; Stokes and Clark, 2001; Piotrowski and others, 2004; King and others, 2009; Christianson and others, 2014; Greenwood and others, 2016; Bjarnadóttir and others, 2017; Kulessa and others, 2017; Simkins and others, 2017), but soft-bed channelized drainage is not included in current ice-sheet models despite efforts to parameterize the governing characteristics.

At present, our understanding of soft-bed hydrological processes is limited. Shoemaker (1986) presented the first mathematical analysis of subglacial hydrology and sediment stability for a soft-bedded ice sheet drained by a combination of porous (groundwater) flow and channelized drainage. He assumed that erosion of sediment at the channel floor would incise channels into the soft bed, but argued that the increase in effective stress on the channel flanks would increase sediment strength sufficiently to make channels stable at any size.

Alley (1992) investigated the mechanical stability of a simplified channel geometry, and applied analytical relationships for till mechanics, including perfect plasticity and Bingham rheology, in part based on parameter fits by Boulton and Hindmarsh (1987). While offering convenience by uniquely linking stress and strain in mathematical models, the weakly non-linear viscous till rheologies proposed by Boulton and Hindmarsh (1987) disagree with the nearly plastic sediment rheology known from fundamental granular and soil mechanics (e.g., Schofield and Wroth, 1968; Nedderman, 1992; Terzaghi and others, 1996; Mitchell and Soga, 2005), field measurements on subglacial till deformation (e.g., Hooke and others, 1997; Kavanaugh and Clarke, 2006), laboratory deformation experiments on till (e.g., Kamb, 1991; Iverson and others, 1998; Tulaczyk and others, 2000a; Iverson and others, 2007), inversion of subglacial mechanics from ice-surface velocities (e.g., Tulaczyk, 2006; Walker and others, 2012; Goldberg and others, 2014; Minchew and others, 2016; Gillet-Chaulet and others, 2016), and numerical experiments (e.g., Iverson and Iverson, 2001; Kavanaugh and Clarke, 2006; Damsgaard and others, 2013, 2016).

Walder and Fowler (1994) combined an earlier mathematical formulation of R-channel closure (Nye, 1976) with the mildly non-linear viscous closure relationship for conduits in till (Boulton and Hindmarsh, 1987; Fowler and Walder, 1993) and derived a new mathematical model for subglacial channels in soft beds. Contrary to the Bingham visco-plastic relationship applied by Alley (1992), Walder and Fowler (1994) ignored sediment yield strength and parameterized till to continuously creep toward the channel and counteract fluvial erosion. In their mathematical framework, they demonstrated that the type of channelized drainage is a function of surface slope. R-channels are likely to form under steep-sloped mountain glaciers, while fluvial incision into the soft bed is hypothesized dominate under relatively flat parts of ice sheets. Ng (2000a) further developed the mathematical theory by Walder and Fowler (1994), and demonstrated that sediment erosion and deposition by fluvial transport is more important than creep closure of the idealized viscous sediment. A similar model, also with viscous till rheology and fluvial channel incision into soft beds, was shown to effectively approximate drainage histories of Antarctic subglacial lakes better than a R-channel model with erosion into the ice base (Carter and others, 2017).

However, the models assuming viscous till rheology provide a continuous flux of sediment towards the channel, and disregard sediment yield strength and associated plastic failure limits. Yet, subglacial till is known to behave 
like other clastic sediments with a nearly perfect plastic and rate-independent rheology with a yield strength $\tau_{y}$ governed by the Mohr-Coulomb constitutive relation, $\tau_{y}=C+N$ tan $\left(\phi_{\mathrm{u}}\right)$, where $C$ is the effective sediment cohesion, $N$ is the effective stress normal to the shear plane, and $\phi_{\mathrm{u}}$ is the angle of internal friction (e.g., Terzaghi, 1943). As a matter of fact, the plastic behavior of sediment beds in general, with or without cohesive forces, is related to the general behavior of granular material (e.g., GDR-MiDi, 2004; Houssais and others, 2015; Houssais and Jerolmack, 2017). In this study, we use numerical simulations of purely granular material (without cohesion) to move one step further in understanding the impact of sediment bed plasticity on the subglacial channel shape dynamics and the subglacial hydrology. In particular, we will study the effect of the effective normal stress at the ice-bed interface, and investigate how strong horizontal pore-pressure gradients toward the channel impact the shape and stability of the channel.

In the next section, we present the physical background of subglacial channel modeling, the simulation method we used, and how simulations of granular material were initialized and performed. Afterwards we present and discuss our results and combine our findings with established approaches for sediment and water in a new continuum formulation for subglacial soft-bed channels.

\section{BACKGROUND AND METHODS}

\subsection{Continuum modeling of subglacial channels}

Mathematical models of subglacial hydrology contain several balance equations, related to conservation of water mass, transients in hydraulic properties related to conduit opening and closure, and conservation of water momentum and energy (e.g., Nye, 1976; Walder and Fowler, 1994; Clarke, 2005; Schoof, 2010; Hewitt, 2011; Kingslake and $\mathrm{Ng}$, 2013; Werder and others, 2013; Flowers, 2015). The cross-sectional size of a soft-bed subglacial channel evolves by the combined effect of melting and creep closure of the channel roof, and fluvial sediment erosion and deposition at the channel base. Here, we assume that the channel is governed by sediment flux alone, implying that the ice interface remains planar. Simultaneous incision of both the ice roof and sedimentary bed, may occur under more energetic conditions (e.g., Alley, 1989; Walder and Fowler, 1994; Carter and others, 2017). Changes in the channel cross-sectional area over time $\partial S / \partial t$ are balanced by the along-channel gradient of fluvial sediment flux $Q_{s}$ through the Exner equation with a representative bed porosity $\Phi$ (e.g., Ng, 2000a):

$$
\frac{\partial S}{\partial t}=\frac{1}{1-\Phi} \frac{\partial Q_{s}}{\partial S}
$$

where $s$ is the channel streamwise dimension. Significant effort has been devoted to constraining the relationships behind sediment transport in fluvial settings, and this is an ongoing topic of research (e.g., Lajeunesse and others, 2010). As a result there are numerous propositions for parameterizing the sediment transport, $Q_{\mathrm{s}}$ (e.g., Shields, 1936; Meyer-Peter and Müller, 1948; Einstein, 1950; Parker, 1978; Stock and Montgomery, 1999; Whipple and Tucker, 1999; Ng, 2000a; Davy and Lague, 2009; Lajeunesse and others, 2010). The commonly used empirical relationships for sediment transport are a function of the shear stress generated by fluid flow near the bed, $\tau$, generally reported as the dimensionless Shields number, $\tau^{*}=\tau /\left[\left(\rho_{\mathrm{g}}-\rho_{\mathrm{w}}\right) g D\right]$ where $\rho_{g}, \rho_{w}, g$, and $D$ are the particle density, fluid density, gravity, and particle diameter, respectively. The onset of sediment transport is classically associated with a critical Shields number, $\tau^{*}{ }_{C}$, that is required to overcome grain friction (Shields, 1936). Meyer-Peter and Müller (1948) is a well-supported sediment transport relationship describing bed-load transport in a turbulent flow:

$$
Q_{\mathrm{s}}=8 \max \left(0, \tau^{*}-\tau_{\mathrm{c}}^{*}\right)^{3 / 2} W \sqrt{\frac{\rho_{\mathrm{g}}-\rho_{\mathrm{w}}}{\rho_{\mathrm{w}}} g D^{3}}
$$

where $W$ is the channel width. Importantly, $\tau^{*}{ }_{\mathrm{c}}$ is highly material dependent, and, in particular, increases as particle sizes become small enough that cohesion forces become significant. We note that the sediment-flux relationship presented above may fall short for very clay-rich or multimodal beds (e.g., Wilcock, 1998; Houssais and Lajeunesse, 2012). The fluid shear stress $\tau$ along the hydraulic perimeter can be inferred through the Darcy-Weisbach formula (e.g., Henderson, 1966; Walder and Fowler, 1994; $\mathrm{Ng}$, 2000a; Creyts and Clarke, 2010; Carter and others, 2017), $\tau=0.125 f^{\prime} \rho_{\mathrm{w}}\left(Q S^{-1}\right)^{2}$, where $f^{\prime}$ is a dimensionless friction factor.

As for hard-bed channel models the water flux $Q$ along the channel length axis $s$ can be described by a turbulent flow law (Hewitt, 2011):

$$
Q=\sqrt{F^{-1} S^{8 / 3}\left(\psi-\frac{\partial P_{\mathrm{c}}}{\partial S}\right)},
$$

where $P_{\mathrm{C}}$ is the averaged effective pressure in the channel, and $\psi$ is the topographically constrained pressure gradient:

$$
\psi=-\rho_{\mathrm{i}} g \frac{\partial(b+H)}{\partial s}-\left(\rho_{\mathrm{w}}-\rho_{\mathrm{i}}\right) g \frac{\partial b}{\partial s} .
$$

Here, $b$ is the bed topography and $H$ is the ice thickness (e.g., Hewitt, 2011), and $F$ is a function of conduit geometry and the Manning friction coefficient $n^{\prime}: F=\rho_{\mathrm{w}} g n^{\prime}\left[2(\pi+2)^{2} / \pi\right]^{2 / 3}$. The water-flow law (Eqn 3 ) is typically rearranged to solve for along-channel change in effective pressure $P_{\mathrm{c}}$ (e.g., $\mathrm{Ng}$, 2000b; Kingslake and Ng, 2013; Carter and others, 2017):

$$
\frac{\partial P_{\mathrm{C}}}{\partial S}=\psi-\frac{F Q^{2}}{S^{8 / 3}} .
$$

The water flux $Q$ in the above equation is usually found from an equation of water conservation, often by assuming water incompressibility, negligible change in water storage along the flow path, and negligible sediment fluxes relative to the water discharge. The change in water flux downstream is given by a local source term, $\dot{m}$ (e.g., Schoof, 2010):

$$
\frac{\partial Q}{\partial s}=\dot{m}
$$

The source term $\dot{m}$ can be comprised several contributions, including influx from the surrounding bed through groundwater seepage, inflow along the ice-bed interface, and input from englacial storage. In the following, we apply a numerical model of granular deformation to explore the 
conditional sediment stability a channel, and tweak the above formulation for channel size (Eqn 1) to capture the essential behavior associated with Mohr-Coulomb plasticity of the subglacial sediment.

\subsection{Grain-scale sediment modeling}

\subsubsection{Model description}

We use a discrete element method (DEM, e.g. Cundall and Strack, 1979; Damsgaard and others, 2013) in order to resolve the sediment mechanics in the bed surrounding an idealized subglacial channel. The DEM is a Lagrangiantype numerical approach of multi-body classical mechanics. Newton's Second Law of motion is explicitly integrated to find translational and rotational acceleration, velocity, and position for each grain through time. For a grain $i$ in contact with $j \in N$ other grains, the sum of forces consists of gravitational pull $\left(\boldsymbol{f}_{\mathrm{g}}\right)$, grain-to-grain elastic-frictional contact forces $\left(\boldsymbol{f}_{\mathrm{n}}\right.$ and $\left.\boldsymbol{f}_{\mathrm{t}}\right)$, and the fluid-pressure force $\left(\boldsymbol{f}_{\mathrm{f}}\right)$,

$$
\frac{\partial^{2} \mathbf{x}^{i}}{\partial t^{2}} m^{i}=\boldsymbol{f}_{\mathrm{g}}^{i}+\sum_{j \in N}\left(\boldsymbol{f}_{\mathrm{n}}^{i, j}+\boldsymbol{f}_{\mathrm{t}}^{i, j}\right)+\boldsymbol{f}_{\mathrm{f}}^{i},
$$

where $\boldsymbol{x}$ is the grain center position, $m$ is the grain mass, and $t$ is the time. A similar equation conserves angular momentum:

$$
\frac{\partial^{2} \boldsymbol{\Omega}^{i}}{\partial t^{2}} l^{i}=\sum_{j \in N}\left(-\left(r^{i} \boldsymbol{n}^{i, j} \times \boldsymbol{f}_{\mathrm{t}}^{i, j}\right)\right)
$$

where $\boldsymbol{n}$ is the grain-contact normal vector, $\Omega$ is the angular particle position, and $l$ is the grain rotational inertia.

The forces from grain interactions $\left(\boldsymbol{f}_{\mathrm{n}}\right.$ and $\left.\boldsymbol{f}_{\mathrm{t}}\right)$ are determined by a Hookean (linear elastic) rheology. The contactnormal interaction force is found from the contact-normal component of the inter-grain overlap distance vector $\boldsymbol{\delta}$ :

$$
\boldsymbol{f}_{\mathrm{n}}^{i j}=-k_{\mathrm{n}} \boldsymbol{\delta}_{\mathrm{n}}^{i, j}
$$

The tangential (contact-parallel) interaction force is similarly found from the contact-tangential component of the overlap distance vector, but is in magnitude limited by the Coulomb frictional coefficient $\mu$ :

$$
\boldsymbol{f}_{\mathrm{t}}^{i j}=-\min \left[k_{\mathrm{t}} \boldsymbol{\delta}_{\mathrm{t}}^{i, j}, \mu\left\|\boldsymbol{f}_{\mathrm{n}}^{i, j}\right\|\right] \frac{\boldsymbol{\delta}_{\mathrm{t}}^{i, j}}{\left\|\boldsymbol{\delta}_{\mathrm{t}}^{i, j}\right\|} .
$$

The contact-normal and tangential travel vectors $\left(\boldsymbol{\delta}_{\mathrm{n}}\right.$ and $\left.\boldsymbol{\delta}_{\mathrm{t}}\right)$ are incrementally adjusted over the duration of a grain-tograin interaction, and continuously corrected in the case of contact rotation. If Coulomb failure occurs at the contact, the tangential travel is readjusted to correspond to a length consistent with Coulomb's condition $\left(\left\|\boldsymbol{\delta}_{\mathrm{t}}\right\|=\mu\left\|\boldsymbol{f}_{\mathrm{n}}\right\| k_{\mathrm{t}}^{-1}\right.$, e.g. Luding, 2008; Radjaï and Dubois, 2011). The contact stiffnesses for the elastic interactions $\left(k_{\mathrm{n}}\right.$ and $\left.k_{\mathrm{t}}\right)$ are, contrary to our previous study using this model (e.g., Damsgaard and others, 2015), determined by scaling against a macroscopic elasticity:

$$
k_{\mathrm{n}, \mathrm{t}}=\frac{E \pi\left(r_{i}+r_{j}\right)}{2}
$$

where $E$ is the Young's modulus, and $r_{i}$ and $r_{j}$ are the radii of two interacting grains. This approach makes the bulk elastoplastic behavior independent of the chosen grain size (Ergenzinger and others, 2011; Obermayr and others, 2013).

The fluid-pressure force on each grain is determined by the local gradient of the water-pressure field $\left(p_{\mathrm{f}}\right)$, as well as buoyant uplift from the weight of displaced fluid (Goren and others, 2011; Damsgaard and others, 2015):

$$
\boldsymbol{f}_{\mathrm{f}}^{i}=-V^{i} \nabla p_{\mathrm{f}}-\rho_{\mathrm{f}} V^{i} \boldsymbol{g}
$$

where $V$ is the grain volume, $\rho_{\mathrm{f}}$ is the fluid density, and $\boldsymbol{g}$ is the gravitational acceleration vector. We ignore other and weaker fluid-interaction forces (Stokes drag, Saffman force, Magnus force, virtual mass force) (e.g., Zhu and others, 2007; Zhou and others, 2010), which become important with faster fluid flow and associated larger Reynolds numbers.

Once the sum of forces (right-hand side of Eqn 7) and torques (right-hand side of Eqn 8) have been determined, we perform explicit and third-order temporal integrations with Taylor expansions in order to determine the new kinematic state (e.g., Kruggel-Emden and others, 2008). The maximum admissible time step is tied to the propagation of seismic (elastic) waves through the granular assemblage, and is determined by the density, size, and elastic stiffnesses in the granular system (e.g., Radjaï and Dubois, 2011):

$$
\Delta t=\frac{\epsilon}{\sqrt{\left(\max \left(k_{\mathrm{n}}, k_{\mathrm{t}}\right) / \min (m)\right)}}
$$

with a constant safety factor $(\epsilon=0.07)$.

\subsubsection{Meltwater in sediment and channel}

We describe pore-water pressure in the sediment by a timedependent diffusion equation with a forcing term related to porosity change. The rate of pressure diffusion scales according to Darcy's law in heterogeneous materials:

$$
\frac{\partial p_{\mathrm{f}}}{\partial t}=\frac{1}{\beta_{\mathrm{f}} \phi \mu_{\mathrm{f}}} \nabla \cdot\left(k \nabla p_{\mathrm{f}}\right)-\frac{1}{\beta_{\mathrm{f}}(1-\phi)}\left(\frac{\partial \phi}{\partial t}+\overline{\boldsymbol{v}} \cdot \nabla \phi\right)
$$

where $p_{\mathrm{f}}$ is the fluid-pressure deviation from the hydrostatic pressure, $\beta_{\mathrm{f}}$ is the adiabatic fluid compressibility, and $\mu_{\mathrm{f}}$ is the fluid dynamic viscosity. The locally averaged grain velocity is denoted $\overline{\boldsymbol{v}}$. The local permeability is denoted $k$ and is determined by empirical relations as a function of local porosity $\phi$ (Goren and others, 2011; Damsgaard and others, 2015). The second term on the right-hand side forces a response in water pressure as local porosity changes, and is corrected for advection of porosity. For the sake of simplicity, the fluid-flow model considers the whole domain as porous, with a very high porosity and permeability in the channel (see Fig. 2). The above equation is not adequate for simulating turbulent water flow and sediment in bedload inside the channel.

We calculate the fluid-phase dynamics (Eqn 14) on an Eulerian and regular grid, superimposed over the granular assemblage. The fluid is fully two-way coupled to the granular phase. The fluid forces the sediment through spatial pressure gradients different from the hydrostatic pressure distribution, and the sediment forces the fluid phase by local changes in porosity (e.g., McNamara and others, 2000; Goren and others, 2011; Damsgaard and others, 2015). Contrary to our previous two-phase modeling studies (Damsgaard and others, 2015, 2016), the fluid grid 


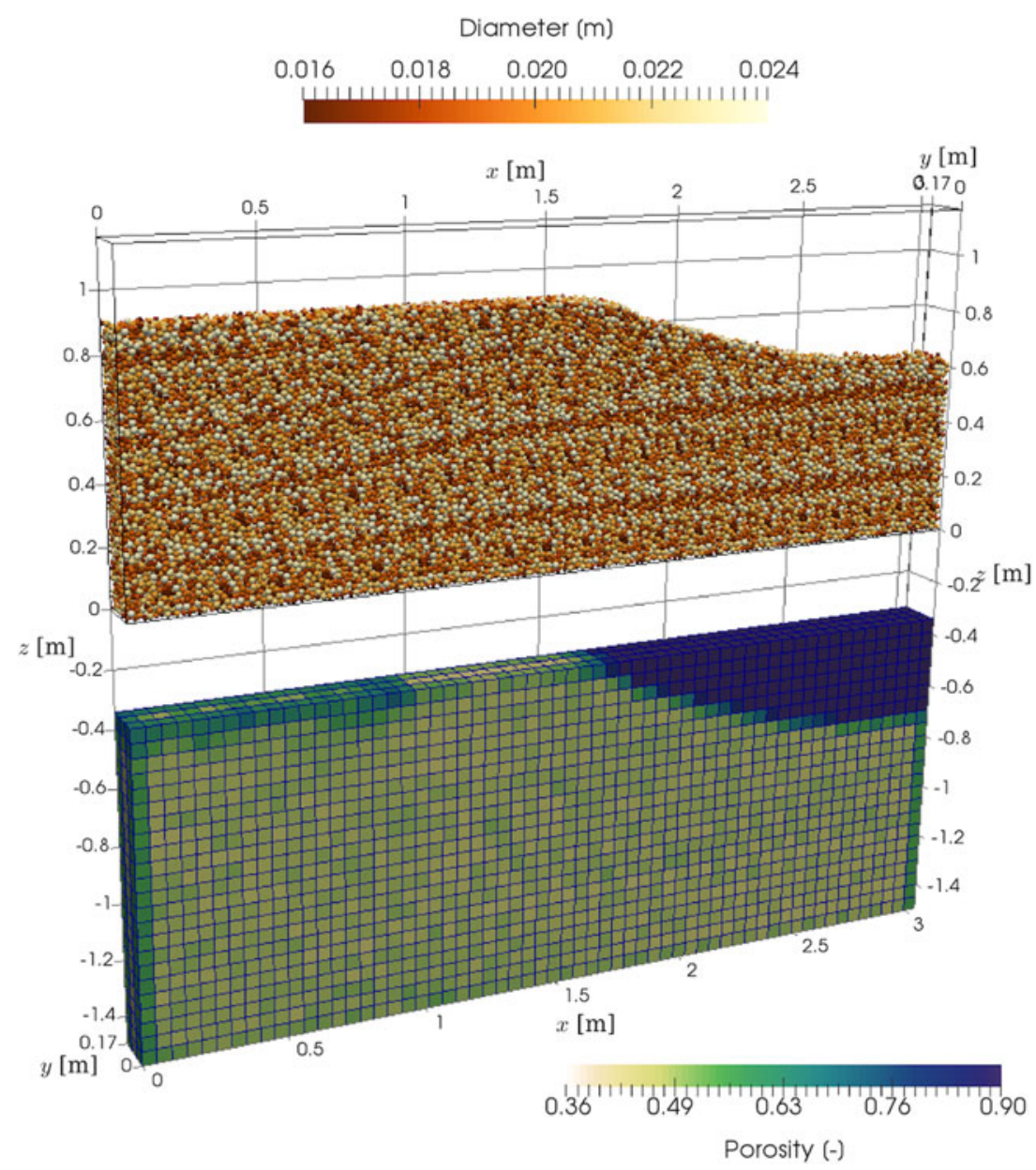

Fig. 2. Overview of the granular assemblage of 58000 particles and the discretization of the fluid grid. We assume symmetry around the channel center $(+x)$ and limit our simulation domain to one of the sides. The model domains of the two phases are superimposed during the simulations.

is adjusted in size to the spatial domain of the granular phase during the simulations in order to correctly resolve the dynamics during volumetric changes, without requiring a constant-pressure boundary condition at the top.

\subsection{Design of numerical experiments}

The purpose of our numerical experiments is to test the hypothesis that sediment dynamics plays an important role in shaping subglacial channels. We design our experiments to simulate the sediment surrounding a channel cavity, which is stressed by a virtual ice-bed interface modeled as a horizontal wall with a pre-defined normal stress. The model is three dimensional in order to correctly resolve grain rotation and interlocking, but the simulation domain is shortened in the along-flow dimension $(y)$ in order to reduce the computational overhead.

We perform dry (water-free) and wet (water-saturated) simulations, with the hypothesis that the presence of water without large pressure gradients does not influence sediment stability, as long as the effective normal stress is equal. The dry simulations (Fig. 3) are designed to inform about steady-state channel geometries under a constant normal stress on the top boundary, which spans the ice-sediment interface and the channel conduit. We perform these simulations without water in order to illustrate pure granular mechanics without transient hardening or softening associated with a pore-fluid pressurization (e.g., Iverson and others, 1998; Moore and Iverson, 2002; Goren and others, 2011; Damsgaard and others, 2015). The omission of fluid in these simulations additionally serves to reduce the required computational time.

For the second set of experiments, we employ wet (watersaturated) simulations (Fig. 4) to investigate sediment stability under various defined water-pressure gradients. The water pressures are kept constant at the channel and at the faraway lateral boundary ( $x=0 \mathrm{~m}$ in Fig. 2$)$, and water pressures are inside the sediment initialized according to a linear interpolation between these Dirichlet boundary conditions. After the initialization procedure, described below, the porosity at the top of the sediment is naturally larger because of the flat ice-bed interface. Additionally, the porosity generally tends to slightly decrease with depth as lithostatic pressure and packing density increases. Local deviations in water pressure from the hydrostatic pressure distribution directly affect the stress balance inside the sediment and at the upper boundary.

The granular assemblage is prepared by letting 1000 uniformly distributed and spherical particles settle in a small cubic volume under the influence of gravity. Afterwards the assemblage is duplicated and repositioned 58 times in space to construct the desired geometry for a total of 58000 grains. We assume that the channel is horizontally symmetrical around its center and simulate half of the channel width. Before proceeding with our main experiments we perform a relaxation step where we allow the 


\section{Solid phase boundary conditions}

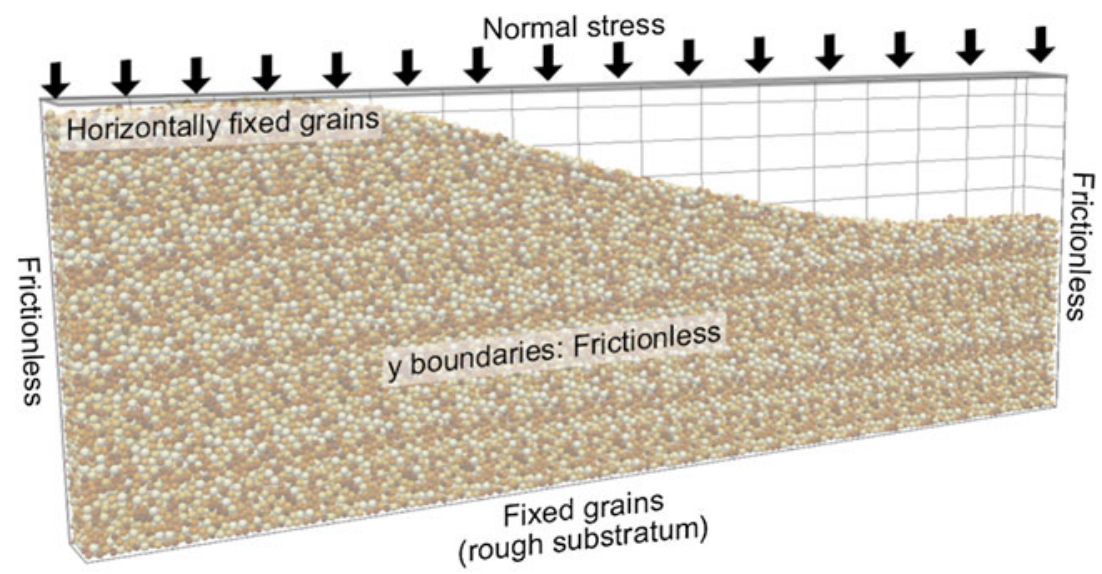

Fig. 3. Boundary conditions and initial state in the presented simulations for the granular phase in the dry experiments. The frictionless lateral boundaries imply no boundary-parallel movement.

grains to settle and adjust their arrangement to the new geometry. Figures 3, 4 show the boundary conditions, as well as the geometry of the simulated sediment at the beginning of the experiments. Table 1 lists the values of the relevant geometrical, mechanical, and temporal parameters.

The governing equation for fluid dynamics (Eqn 14) is in its standard form singular for areas that do not contain grains $(\phi=1)$, such as the channel cavity. We therefore impose an upper limit on porosity of $\phi=0.9$ in Eqn (14) and the other fluid-related equations in order to allow our fluid-phase formulation to work for the channel conduit. Nonetheless, the strong non-linearity of the permeability relation $(k=3.5 \times$ $\left.10^{-13} \mathrm{~m}^{2} \phi^{3}(1-\phi)^{-2}\right)$ causes much faster diffusion of fluid pressures in the conduit than internally in the sediment, consistent with our expectations of how the hydraulic system should behave. However, we are for the purposes of this study mainly interested in the mechanical behavior of the sediment surrounding the channel. Similarly, we do not resolve water flow along the channel length axis, but focus our experimental analysis of grain-fluid interaction inside of the sediment with the channel cavity acting more as a boundary condition.

We choose a relatively low value for Young's modulus in Eqn (11) in order to increase the computational time step

Solid phase boundary conditions

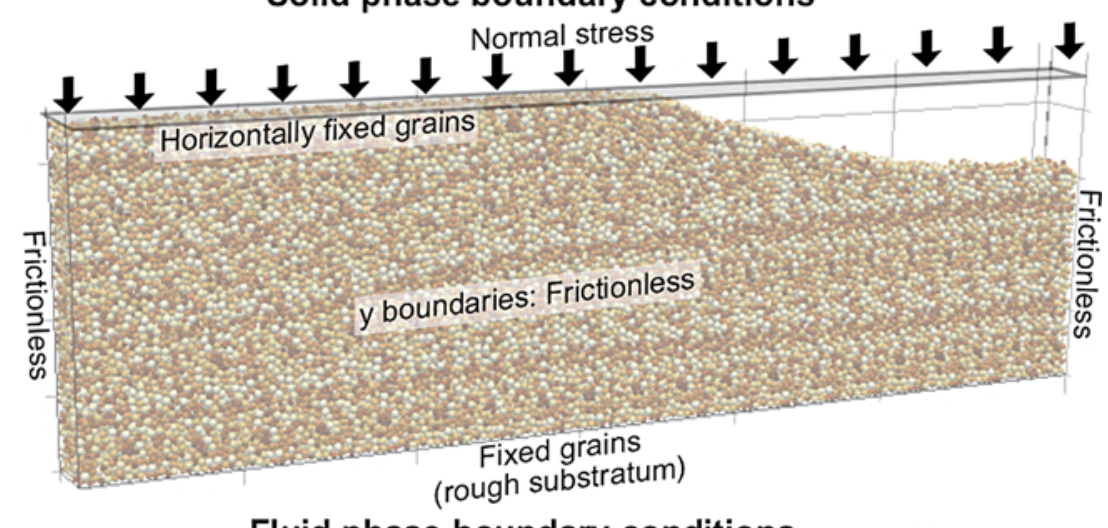

Fluid phase boundary conditions

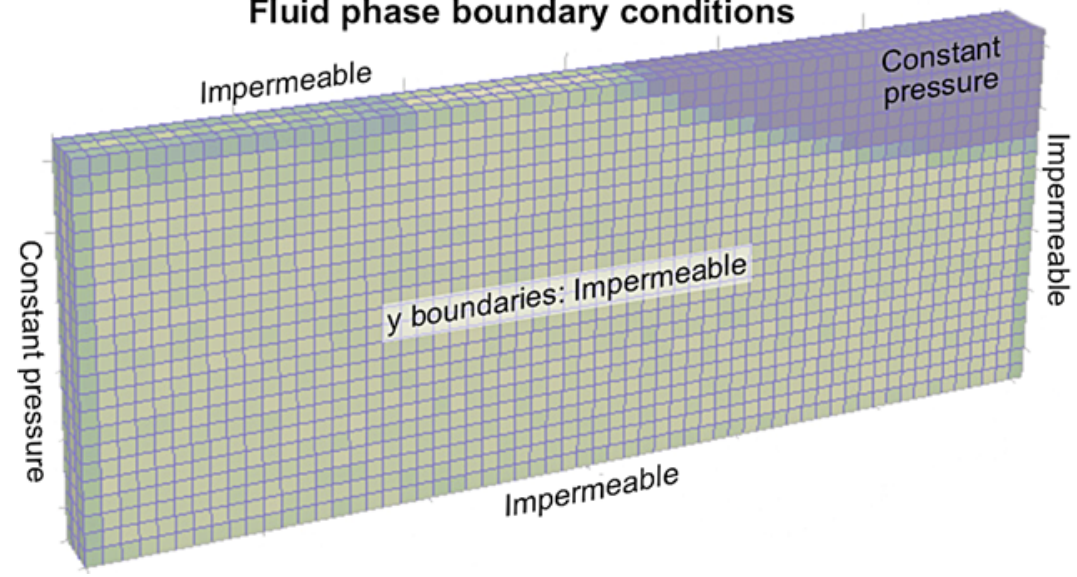

Fig. 4. Boundary conditions and initial state in the presented simulations for the granular and fluid phases in the wet experiments. 
Table 1. Simulation parameters and their values for the granular experiments

\begin{tabular}{lll}
\hline Parameter & Symbol & Value \\
\hline Grain count & $N_{\mathrm{p}}$ & 58000 \\
Grain radius & $r$ & 0.008 to $0.012 \mathrm{~m}$ \\
Grain Young's modulus & $E$ & $7.0 \times 10^{8} \mathrm{~Pa}$ \\
Grain friction coefficient & $\mu$ & 0.5 \\
Grain density & $\rho_{\mathrm{g}}$ & $2600 \mathrm{~kg} \mathrm{~m}^{-3}$ \\
Fluid density & $\rho_{\mathrm{w}}$ & $1000 \mathrm{~kg} \mathrm{~m}^{-3}$ \\
Fluid dynamic viscosity* & $\mu_{\mathrm{f}}$ & $1.797 \times 10^{-6} \mathrm{~Pa} \mathrm{~s}^{*}$ \\
Fluid adiabatic compressibility & $\beta_{\mathrm{f}}$ & $1.426 \times 10^{-8} \mathrm{~Pa}^{-1}$ \\
Hydraulic permeability prefactor & $k_{\mathrm{c}}$ & $3.5 \times 10^{-13} \mathrm{~m}^{2}$ \\
Spatial domain dimensions & $\boldsymbol{L}$ & {$[3.0 ; 0.17 ; 0.91] \mathrm{m}$} \\
Gravitational acceleration & $\mathbf{g}$ & {$[0 ; 0 ;-9.81] \mathrm{m} \mathrm{s}^{-2}$} \\
Computational time step* & $\Delta t$ & $1.44 \times 10^{-6} \mathrm{~s}$ \\
Simulation length* & $t_{\mathrm{end}}$ & $10 \mathrm{~s}$ \\
& & \\
\hline
\end{tabular}

* Simulation time and time-dependent parameters are listed in scaled model time, see Damsgaard and others $(2015,2016)$.

(Eqn 13 and Table 1), but the resultant elastic softening has negligible effect on porosity and mechanical behavior. Compressive strain on grain contacts is in our model due to the softening expected to be a hundred times greater than theoretical values for quartz, but the actual strains remain very small $\left(2 \times 10^{-3} \%\right.$ of the grain radius under a compressive stress of $10 \mathrm{kPa}$ ). Furthermore, we chose a relatively large grain size and narrow grain-size distribution to increase computational efficiency during the grain-to-grain contact searches. At the same time, the hydraulic properties are decoupled from sediment size to allow for low-permeability simulations with relatively large grains (Goren and others, 2011; Damsgaard and others, 2015). We do note that the simplification in grain size, shape, and morphology will influence granular deformation patterns and sediment frictional properties (e.g., Iverson and others, 1998; Damsgaard and others, 2013). We also omit tensile interactions between grains giving cohesionless behavior. However, apparent cohesion observed in laboratory shear tests on real geological materials often vanishes at very low normal stresses (e.g., Schellart, 2000), making grain-tension less important at free sediment surfaces.

We assume that channels in subglacial beds inherently form due to flow instabilities by differential erosion, similar to the processes driving distributed flow to R-channel drainage on hard beds. Intrinsic channelization during fluid flow has been demonstrated in physical dam-breach experiments (e.g., Walder and others, 2015) and in smaller experimental studies (e.g., Catania and Paola, 2001; Mahadevan and others, 2012; Kudrolli and Clotet, 2016; Métivier and others, 2017). Channelization occurs when fluid flux is able to erode the porous medium through which it is flowing. In turn, this process reduces local friction against the fluid flux and further enhances flow localization. In this study, we investigate the mechanical state and deformation patterns around an already established channel conduit incised into the sedimentary bed, and are not able to include the process of channel formation itself.

\section{RESULTS}

We do not observe significant differences in steady-state channel geometry between the dry and wet simulations at equal effective normal stresses, which is expected as the fluid only affects the granular force balance in the presence of water-pressure gradients (Eqn 12). However, the wet simulations take three times longer to complete.

In the dry experiments, we observe that the effective normal stress on the channel flanks results in rapid failure, occurring over a few seconds (Fig. 5). Larger normal stresses result in more deformation. Consistent with sediment plasticity, the deformation stops when a new stress balance has been established. The final and steady-state geometries are shown in Figure 6, where larger normal stresses result in smaller channel cavities. We do expect slow creep in the sediment, especially if there are large fluctuations in water pressure and granular stresses (Pons and others, 2015; Damsgaard and others, 2016) or strong water flow (Houssais and others, 2015, 2016). However, the associated creep is expected to occur with a significantly more nonlinear rheology than previously used for soft-bed channels (e.g., Alley, 1992; Walder and Fowler, 1994; Ng, 2000b; Carter and others, 2017), and we do not detect measurable creep on the timescales considered here (Fig. 5).

We can describe the relationship between the imposed effective normal stress and observed maximum channel width reasonably well by a linear fit (Fig. 7):

$$
W_{\max }=(a N+b)
$$

with fitting parameter values $a=-0.118 \mathrm{~m} \mathrm{kPa}^{-1}$ and $b=$ $4.60 \mathrm{~m}$ (associated standard deviations (std dev.) reported in Fig. 7). By assuming a simple geometry where the slope of the channel flanks is given by the sediment angle of repose $\theta$ (Fig. 8), we can approximate the limit to channel the cross-sectional area, $S_{\max }$ as a function of the channel width:

$$
S_{\max }=\frac{1}{4} W_{\max }^{2} \tan \theta
$$

We constrain the channel size in the continuum channel model (Eqns 1-6) in order to capture the stress-based limits.

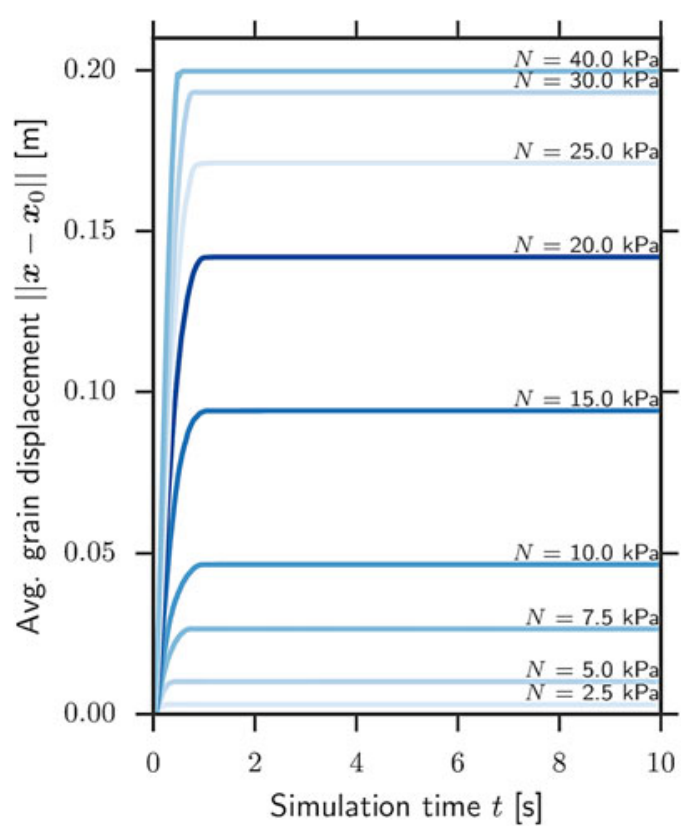

Fig. 5. Averaged grain displacements through time for a range of effective normal stresses, $N$ in the dry granular experiments. 


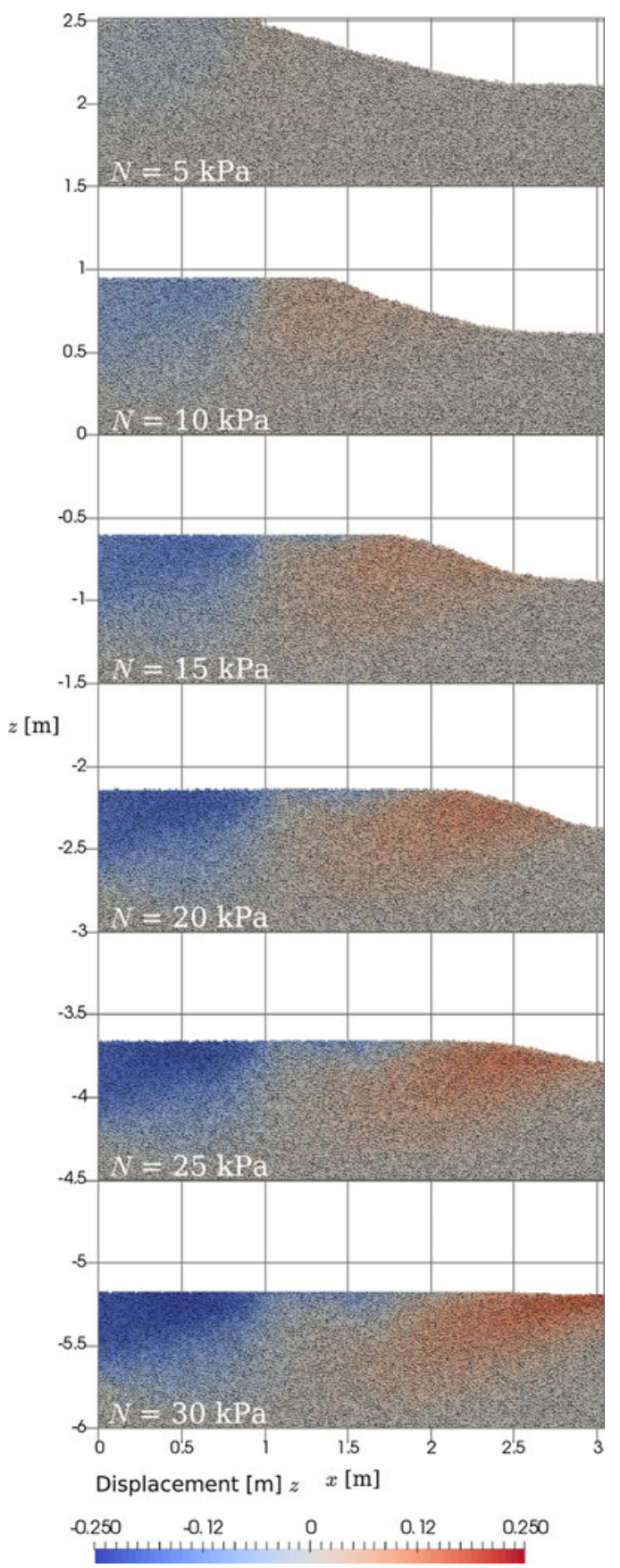

Fig. 6. Channel geometries in the steady state at different effective normal stresses $N$ in dry experiments. Grains are colored according to their cumulative vertical displacement and rendered in an orthogonal projection. The absence of water does not influence the steady-state geometry unless the sediment is flushed by strong water-pressure gradients.

We do not view extrapolation of the channel width below the tasted range $(N=[2.5 ; 40] \mathrm{kPa})$ as physically meaningful. Geometries with slopes beneath the angle of repose should be stable without load from the ice overburden under events with overpressurized water $(N \leq 0 \mathrm{kPa})$, allowing for the existence of larger subglacial cavities.

The grain-scale stress balance (Fig. 9) shows that stresses from the ice load on channel flanks are transmitted predominantly downwards, and do not affect the stress balance in the sediment beneath the channel conduit. The sediment beneath the channel conduit is loaded exclusively by its own weight (lithostatic pressure), which increases linearly

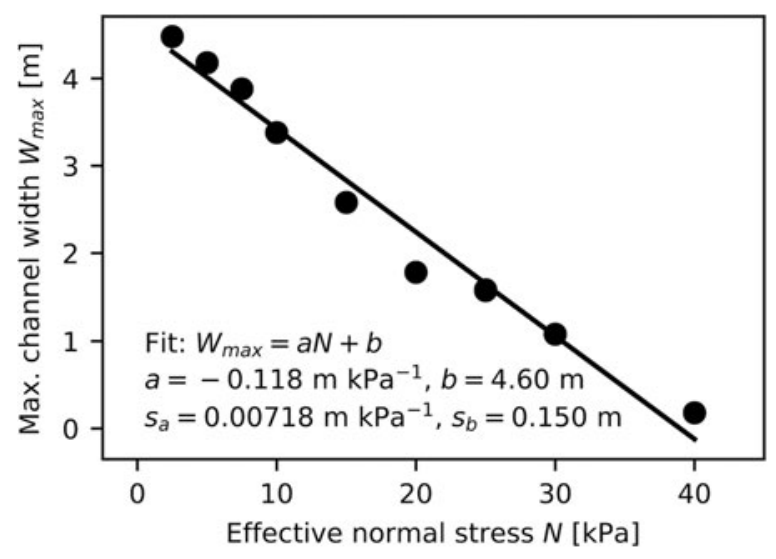

Fig. 7. Observed maximum channel width, $W_{\max }$, under a constant imposed value for effective normal stress, $N$. Data points are fitted using a non-linear least-squares fit, with fitted parameter values and their corresponding std dev. noted.

with depth. This behavior contrasts with viscous till models, that assume that the stress on the channel flanks contributes to till uplift at the bottom of the channel.

In our wet simulations, forced with water-pressure differences between channel and bed, the pressure-gradients create drag forces on the grains oriented towards the channel (Fig. 10). The presence of smaller water-pressure gradients cause minor sediment rearrangement, but deformation rapidly decays and the channel continues to be stable (Fig. 11, left and center). The channel geometry is not significantly different from the dry experiment under small water-pressure gradients (compare the simulation with $N=10 \mathrm{kPa}$ in Fig. 6 with Fig. 11, left and center). However, when larger pressure gradients are prescribed the sediment flushes into the channel, causing rapid channel infill and closure (Fig. 11, right).

Figure 12 shows the results of an example implementation of the continuum channel model (Eqns 1-6, with limits to channel size imposed by Eqns 15 and 16). The solution is found iteratively with a Dirichlet boundary condition of $P_{\mathrm{C}}=0 \mathrm{~Pa}$ at the terminus. Gradients are estimated with upwind finite difference approximations. We assume that channel effective pressure $\left(P_{\mathrm{c}}\right)$ equals the magnitude of the effective normal stress on the channel flanks $(N)$. In real settings channel effective pressure will most commonly be slightly higher than normal stress on the flanks $\left(P_{\mathrm{c}}>\|\mathbf{N}\|\right)$, as water pressure differences cause dominant water flow towards the channel.

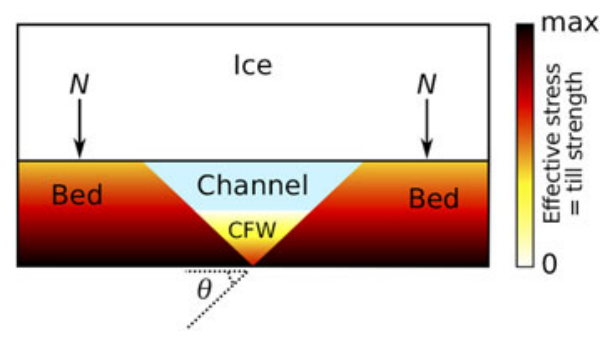

Fig. 8. Idealized schematic of effective stress magnitude and till yield strength in a cross-section around a subglacial channel incised in the sedimentary bed. Sediments beneath the channel floor are not stressed by ice weight on the flanks, and comprise a weak channel floor wedge (CFW). 


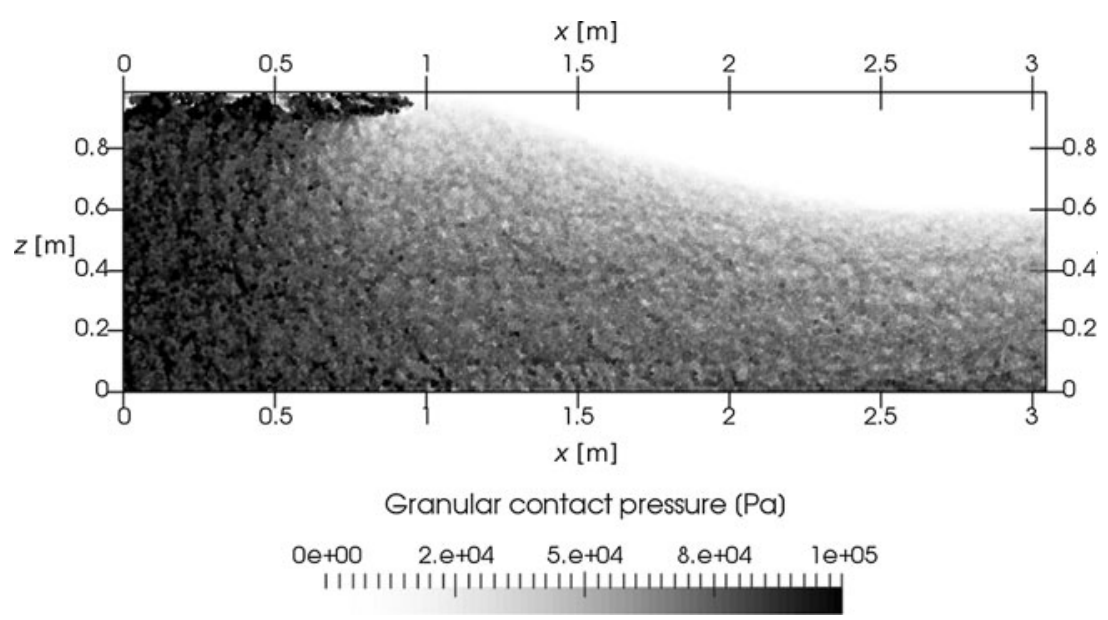

Fig. 9. Contact pressure on the grains $\left(\sum\left\|\boldsymbol{f}_{\mathrm{n}}\right\| 4 \pi r^{2}\right)$ in the steady state with an effective stress of $N=7 \mathrm{kPa}$.

In this example, the water fluxes are increasing downstream due to the water supply $(\dot{m})$. The increasing water flux generally increases the sediment-bedload flux $\left(Q_{\mathrm{s}}\right)$ downstream. At $s=0$ to $0.8 \mathrm{~km}$ the large effective pressures $\left(P_{\mathrm{c}}\right)$ inhibit channel development due to sediment failure. Close to the margin $(s=0.8-1.0 \mathrm{~km})$ the effective pressure is sufficiently low to allow for channel existence. The

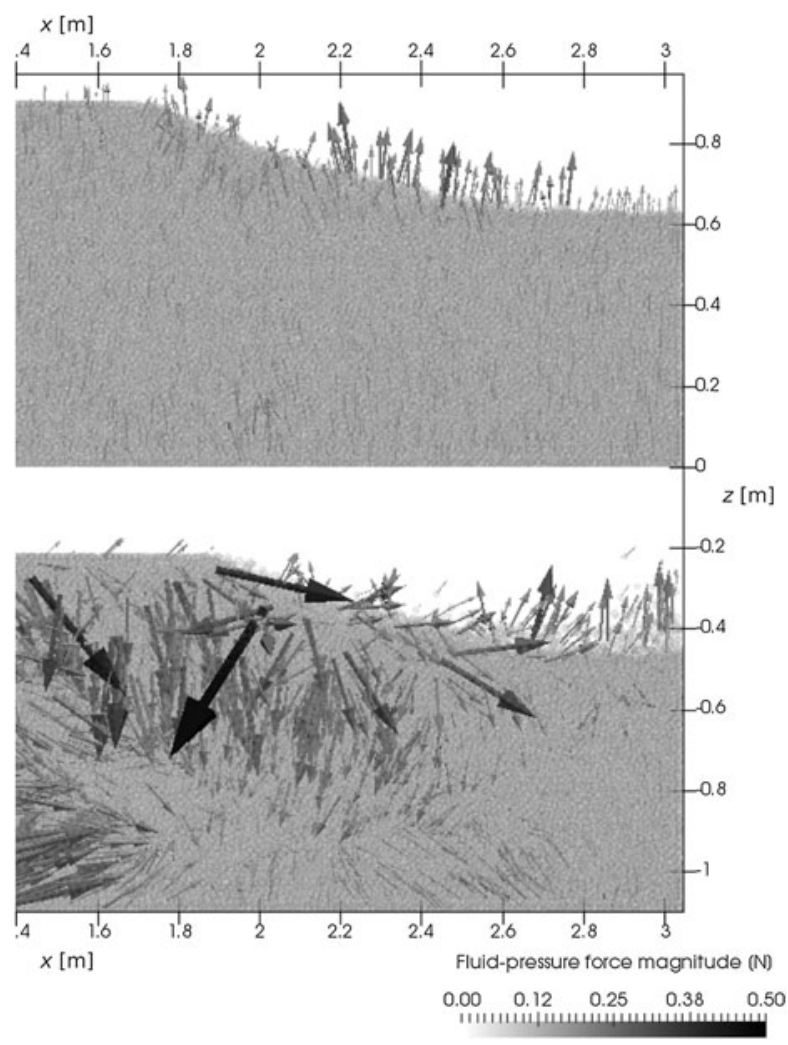

Fig. 10. Fluid-pressure forces (Eqn 12) on the individual sediment grains visualized by arrows. Top: Under low gradients in porewater pressure (here $d p_{\mathrm{f}} / d x=-0.1 \mathrm{kPa} \mathrm{m}^{-1}$ ), the fluid-pressure force primarily contributes weak buoyant uplift on the grains. Bottom: Larger pressure gradients $\left(d p_{\mathrm{f}} / d x=-10 \mathrm{kPa} \mathrm{m}^{-1}\right)$ destabilize the sediment through liquefaction at the channel floor and cause collapse of the sediment with associated chaotic interactions (e.g., large internal forces). Individual force vectors are not representative of the grain ensemble and should not be interpreted directly. Both simulation snapshots are from $t=1.5 \mathrm{~s}$. increase in channel cross-sectional size near the margin decreases the fluvial shear stress and causes a rapid drop in fluvial sediment flux $Q_{s}$.

\section{DISCUSSION}

We have demonstrated that sediment yield strength can prevent collapse of channels. Because of sediment plasticity, channel erosion into subglacial sediments is not balanced by a continuous flux of viscous till deformation into the channel cavity, which was assumed in prior parameterizations (e.g., Fowler and Walder, 1993; Walder and Fowler, 1994; $\mathrm{Ng}$, 2000b). Instead, channel cross-sectional geometry is governed by fluvial erosive and depositional dynamics until channel size is limited by sediment yield strength.

Infilled fossil subglacial channels seen in field sections along the southern margin of the last Scandinavian Ice Sheet (Fig. 13) show similar geometry to the stable channel conduits observed in our granular experiments (e.g., Figs 6, 11), where the sediment angle of repose is a principal control on channel cross-sectional geometry. The channel sizes observed in the field (Fig. 13) are within the limits observed in our granular experiments (Fig. 7) and the simplified ice-marginal area of our continuum channel model (Fig. 12).

While Shoemaker (1986) assumed that the bed would strengthen against failure under high effective stresses, we show that the magnitude of effective stress on the bed surrounding the channel puts an upper limit on channel dimensions. The exact relationship between effective normal stress and channel size (Fig. 7) will be material dependent, and the granular model applied here includes several simplifying assumptions related to grain size and grain shape. The grain angularity and size distribution in subglacial tills might result in slightly larger yield strengths and allow for the existence of larger channels. Overconsolidation of subglacial tills additionally contributes to shear strength (e.g. Tulaczyk and others, 2000a), which will increase stability and limits to channel size. However, the stress-size relationship presented here should be a reasonable approximation for a simple model. While our results are based on numerical experiments on simplistic granular materials, our interpretation stands that it is unlikely for soft-bed channels to exist at effective subglacial normal stresses more than $\sim 100 \mathrm{kPa}$ in magnitude (Fig. 7). We propose that the constrained 


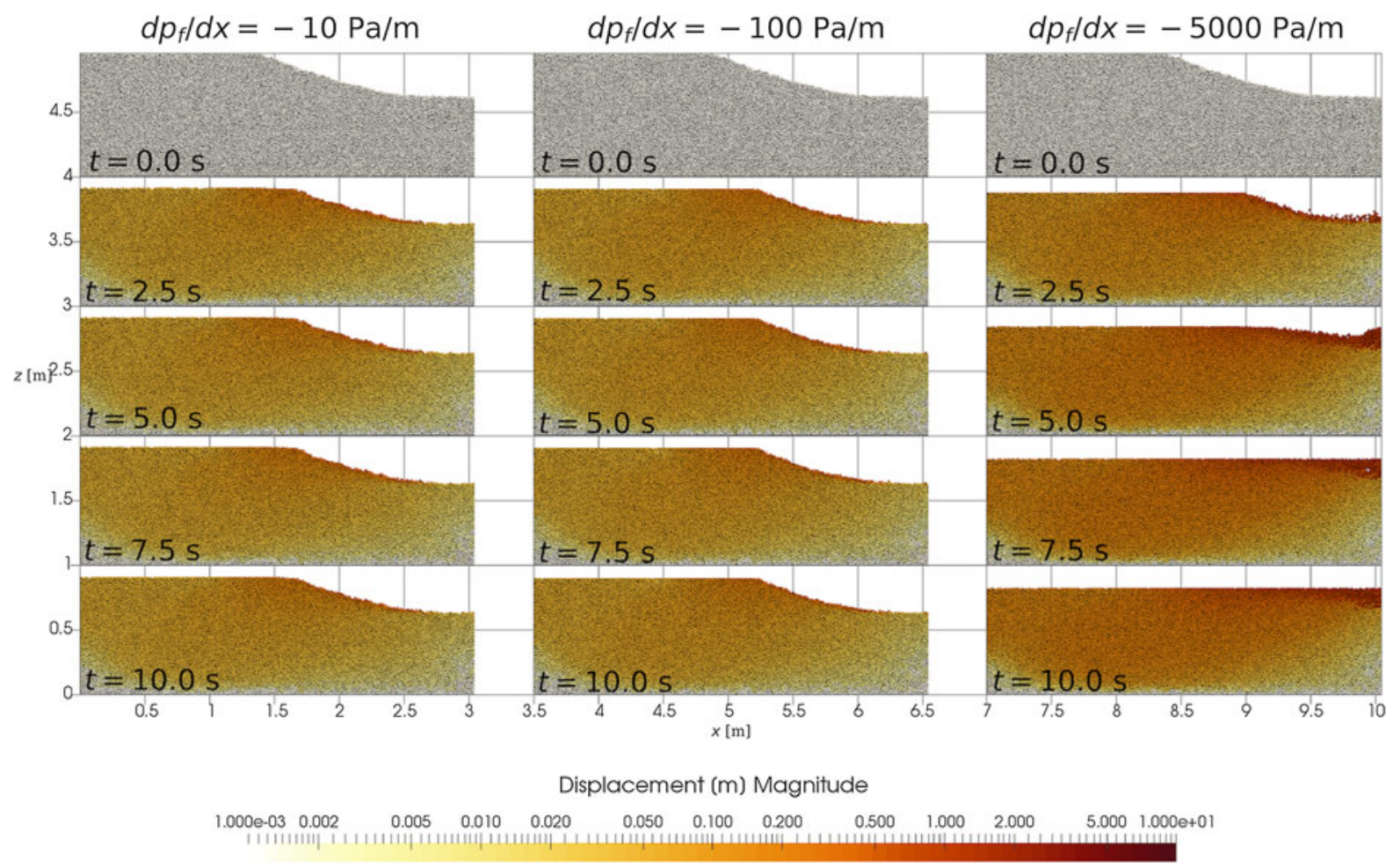

Fig. 11. Total per-grain spatial displacements at different times for three wet (water-saturated) simulations with different imposed waterpressure gradients and an effective stress of $N=10 \mathrm{kPa}$. The water-pressure gradients cause flow and drag forces toward the channel, and destabilize the conduit at higher values.

relationship between channel geometry and effective normal stress makes it theoretically possible to asses water pressure and hydrological conditions under past ice sheets, e.g. when meltwater channels are identified from geomorphological interpretation of subaerial or subaqueous topography (e.g., Lesemann and others, 2010; Greenwood and others, 2016; Bjarnadóttir and others, 2017), or from channel-sediment geometries in the glaciogeological sedimentary record (e.g., Piotrowski, 1999; Tylmann and others, 2013).

Ice overburden stress does not impact the sediments beneath the channel floor directly; the compressive stress acting on channel-floor sediments is a result of their own weight as lithostatic pressure increases with depth (Fig. 9). Sediment dynamics at the floor of subglacial channels are then similar to those in subaerial rivers, although the drainage system arrangement may differ (Catania and Paola, 2001; Métivier and others, 2017). Due to the plastic rheology of sediment, erosion of the channel floor will be counteracted by an immediate sediment response when the channel is at its size limit, acting to reestablish stress balance in the bed surrounding the channel. If differential sediment advection toward the cavity bends the ice-bed interface downwards progressively, the resultant channel landform of erosive origin is likely to appear wider than the channel cavity itself (Boulton and Hindmarsh, 1987; Ng, 2000b).

The evolution of subaerial river size is governed by feedbacks and stability limits (e.g. Métivier and others, 2017). We conclude that there are two distinct feedbacks stabilizing subglacial channel size on soft beds: (1) If a channel becomes sufficiently efficient in evacuating subglacial meltwater, the pore-water pressure decreases and the effective normal stress on the surrounding areas of the bed increases. If this stress increase causes the channel size to exceed the stability limit, the channel spontaneously reduces in size which decreases the hydrological transport capacity which, in turn, can increase the water pressure and decrease the effective normal stress. (2) For a given water flux, an increase in channel cross-sectional size due to fluvial erosion decreases the water-driven shear stress on the channel bottom. The decrease in shear stress decreases sediment transport (Eqn 2), which decreases channel growth (decreasing $\partial Q_{s} / \partial s$ in Eqn 1). These feedbacks may ultimately lead to stabilization of subglacial sliding and hydrology, tied to the plastic failure limit of the bed and the basal hydraulic transmissivity.

For the subglacial drainage model presented here, we consider channelized flow alone although it could be significantly improved by coupling it to a diffusive flow model accounting for sheet flow at the ice-bed interface, groundwater flow, and/or R-channel incision (e.g., Creyts and Schoof, 2009; Hewitt, 2011; Werder and others, 2013; Flowers, 2015). Furthermore, the parameterization for water flux in the channel can be improved by including both laminar and turbulent descriptions, dependent on the Reynolds number of the water flow (e.g., van der Wel and others, 2013).

With increasing subglacial discharge, we expect a hydraulic transition from distributed drainage to sedimentincised channels (e.g., Mahadevan and others, 2012; Kudrolli and Clotet, 2016). However, yield failure of the channel flanks imposes a limit to their cross-sectional area and hydraulic transport capacity. If the hydraulic transmissivity becomes insufficient against the water fluxes, we either expect R-channel incision into the ice base, or the formation of multiple parallel drainage channels incised into the sediment. If subglacial soft-bed channels were able to grow 

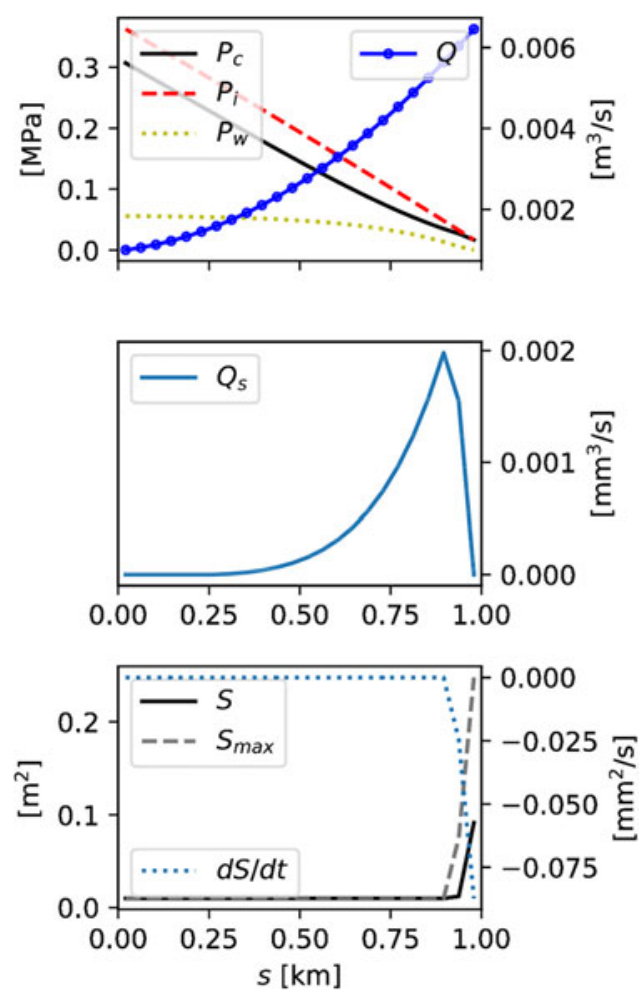

Fig. 12. Example run of the soft-bed subglacial channel model outlined in Eqns (1-6, 15 and 16), with a square-root ice geometry and linearly increasing meltwater influx $(\dot{m})$ towards $+s$. Top: Channel effective pressure $\left(P_{\mathrm{c}}\right)$, ice-overburden pressure $\left(P_{\mathrm{i}}\right)$, water-pressure $\left(P_{\mathrm{w}}\right)$ and water flux $(Q)$. Middle: Sediment flux increases non-linearly with water flux (Eqn 2). Bottom: Maximum $\left(S_{\max }\right)$ and actual channel cross-sectional size $(S)$, together with channel growth rate $(d S / d t)$. This example is with a constant forcing and $t=2$ days. The minimum channel size is set to $S=$ $0.01 \mathrm{~m}^{2}$ for numerical considerations. In this example the sediment yield strength prevents channel existence except near the terminus where effective pressure is relatively low.

without size constraints, it would be thermodynamically more efficient to gather drainage in fewer and larger channels.

An arrangement of closely spaced channel drainage is observed at Glaznoty, north-central Poland, where the channel in Figure 13 is one of a series of small, similarsized channels occurring at the paleo-ice-bed interface. Parallel sediment landforms (glacial curvilineations) have been observed from under the palao-Scandinavian Ice Sheet (Fig. 1, Lesemann and others, 2010, 2014), which may be governed by the channel-size limits described here. Furthermore, radar-echo soundings of the sedimentary bed of Thwaites Glacier, West Antarctica have been interpreted to reflect hydraulic transitions between few to many parallel and closely spaced channelized drainage elements incised into the sedimentary bed (Schroeder and others, 2013). We do note that the landforms and channel-drainage elements observed in the glacial curvilineations are generally larger than what is predicted from our limits related to plastic failure (Fig. 7). We believe that this discrepancy is mainly related to the fact that the numerical material with spherical and smooth grains is mechanically weaker than subglacial tills with elongated and angular grains.

Liquefaction at the earth surface and in subaqueous environments is known to be initiated by overpressurization in the
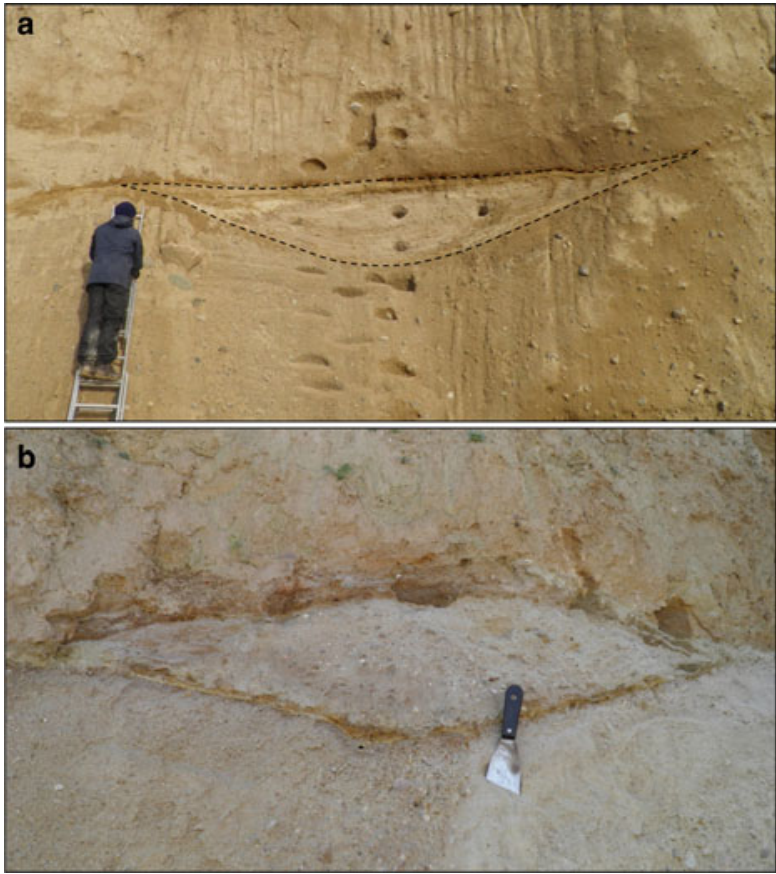

Fig. 13. Examples of infilled subglacial channels in the southern, marginal part of the Scandinavian Ice Sheet from the last glaciation (Piotrowski et al., in prep.). (a) Subglacial channel at Ebeltoft, Djursland, Denmark. The channel is found within a single till unit about $10 \mathrm{~km}$ inside the ice margin. It is flat-topped and filled with parallel-bedded outwash sand and gravel intercalated with layers of silt. Single outsized stones, possibly dropped from the channel roof are randomly dispersed in the outwash deposit. Along the channel bottom and on its left-hand side the infill material is deformed into attenuated folds, irregular detached sediment pods and flame structures. Since the flanks of the channel are below the angle of repose of sand, the deformation structures suggest syndepositional sediment intrusion into the channel driven by a pressure gradient oriented toward the channel axis. (b). Subglacial channel at Glaznoty, north-central Poland, about $25 \mathrm{~km}$ within the ice limit. The channel occurs at the interface between proglacial outwash deposits (below) and till (above). The channel is distinctly lens-shaped with an upwardconvex top suggesting an R-channel incised upward into the ice at a late stage of formation. It is infilled with massive coarse-grained sand and gravel.

pore space, effectively reducing the compressive stress to low or even negative values (e.g., Zhang and Campbell, 1992; Terzaghi and others, 1996; Xu and Yu, 1997; Mitchell and Soga, 2005). In situ measurements of subglacial water pressure indicate that water pressures are highly variable through time (e.g., Hooke, 1984; Engelhardt and Kamb, 1997; Hooke and others, 1997; Bartholomaus and others, 2008; Andrews and others, 2014; Schoof and others, 2014). We propose that events of liquefaction in subglacial channels may be common when water-pressure in the channel rapidly decreases, and this process may be able to make significant volumes of weak sediment from the channel-floor wedge available for fluvial transport, especially in sedimentary beds with low permeability that require long timescales to respond to changes in interfacial water pressure.

As previously discussed, we are not able to include the effect of subglacial deformation due to ice movement along the channel length, which might be important for long-term channel stability. We do note that subglacial shear could 
be included by setting the $y$ boundaries to be periodic (e.g., Damsgaard and others, 2013), but the spatial domain length along $y$ in the current setup is too short to allow for shearing without geometrical instabilities. Sediment advection associated with shear deformation causes frictional heating and granular diffusion (e.g., Hooyer and Iverson, 2000; Utter and Behringer, 2004); these process are likely to drive channel closure with a rate proportional to the shear-strain rate in the sediment. We also assume that the ice-bed interface remains flat and rigid over time, while Ng (2000b) demonstrated that differential ice and till advection toward the channel conduit bends the interface over longer timescales. Our model approach could be improved by simulating a dynamically evolving ice-bed interficial geometry. However, we believe that inclinations in the ice-bed interface are unlikely to fundamentally alter the principal stresses in the surrounding sediment, and assume that the ice is responding elastically over the timescales investigated in the experiments $(<1 \mathrm{~min})$.

\section{CONCLUSIONS}

Current relationships for subglacial channel dynamics incised into sedimentary beds assume linear to mildly nonlinear viscous relationships for till rheology, which results in continuous sediment flux toward the channel balancing erosion by water flow. However, sediments are known to be nearly perfect plastic with a yield strength dependent on the confining stress.

We have coupled two separate models to gain a multiscale understanding between sediment deformation and subglacial channel stability. Our granular model informs about sediment stability under different effective normal stresses and water-pressure forcings. We observe that the channel conduit size is strongly limited by the magnitude of effective normal stress on the channel flanks, and that creep closure is negligible. The compressive stresses from the ice-bed interface on the channel flanks are oriented subvertically instead of being directed towards the channel floor. The channel-flooring sediments are only compacted by their own weight. Strong water-pressure differences between the channel and its surrounding parts can cause horizontal infilling by sediment movement along the ice-bed interface.

We use the results from our granular simulations to include effects of sediment plasticity in a continuum model of soft-bed subglacial channels. The channel size is limited by the yield strength of the sediment, which in turn depends on effective normal stress on the channel flanks. The size limit implies that multiple closely spaced channels are needed for transporting large amounts of water, which corresponds to geophysical observations under contemporary ice sheets and geomorphological signatures from previously glaciated areas. The presented continuum model for channelized drainage, derived from our suite of numerical simulations, increases the realism of hydrology models for ice sheets and glaciers residing on soft beds.

\section{ACKNOWLEDGMENTS}

A. Damsgaard was supported by a postdoctoral fellowship by the Cecil H. and Ida M. Green Foundation and NSF-PLR1543396. A. Damsgaard acknowledges the NVIDIA Corporation for a hardware grant and the Extreme Science and Engineering Discovery Environment (XSEDE) for a high-performance computing startup allocation. In preparation for this paper, A. Damsgaard has benefited from discussions with C. W. Elsworth, L. Goren, I. J. Hewitt, S. P. Carter, A. Cabrales-Vargas, and V. Tsai. We thank Jonathan Kingslake and anonymous reviewer for constructive comments, which improved the manuscript and Neil Glasser for handling the editorial process.

\section{REFERENCES}

Alley KE, Scambos TA, Siegfried MR and Fricker HA (2016) Impacts of warm water on Antarctic ice shelf stability through basal channel formation. Nat. Geosci., 9(4), 290-293

Alley RB (1989) Water-pressure coupling of sliding and bed deformation: I. Water system. J. Glaciol., 35(119), 108-118

Alley RB (1992) How can low-pressure channels and deforming tills coexist subglacially? J. Glaciol., 38, 200-207

Alley RB, Blankenship DD, Bentley CR and Rooney ST (1986) Deformation of till beneath ice stream B, West Antarctica. Nature, 322, 57-59

Alley RB, Lawson DE, Larson GJ, Evenson EB and Baker GS (2003) Stabilizing feedbacks in glacier-bed erosion. Nature, 424 (6950), 758-760

Anandakrishnan S, Blankenship DD, Alley RB and Stoffa PL (1998) Influence of subglacial geology on the position of a West Antarctic ice stream from seismic observations. Nature, 394 (6688), 62-65

Andrews LC and 7 others (2014) Direct observations of evolving subglacial drainage beneath the Greenland Ice Sheet. Nature, 514, 80-83

Bartholomaus TC, Anderson RS and Anderson SP (2008) Response of glacier basal motion to transient water storage. Nat. Geosci., 1(1), 33-37

Bartholomew I and 5 others (2010) Seasonal evolution of subglacial drainage and acceleration in a Greenland outlet glacier. Nat. Geosci., 3(6), 408-411

Bindschadler R (1983) The importance of pressurized subglacial water in separation and sliding at the glacier bed. J. Glaciol., 29(101), 3-19

Bjarnadóttir LR, Winsborrow MCM and Andreassen K (2017) Large subglacial meltwater features in the central Barents Sea. Geology, 45(2), 159-162

Bougamont M, Price S, Christoffersen P and Payne AJ (2011) Dynamic patterns of ice stream flow in a 3-D higher-order ice sheet model with plastic bed and simplified hydrology. J. Geophys. Res. Earth Surf., 116(F04018)

Bougamont M and 5 others (2015) Reactivation of Kamb Ice Stream tributaries triggers century-scale reorganization of Siple Coast ice flow in West Antarctica. Geophys. Res. Lett., 42(20), 8471-8480

Boulton GS and Hindmarsh RCA (1987) Sediment deformation beneath glaciers: rheology and geological consequences. J. Geophys. Res., 92(B9), 9059-9082

Boulton GS, Hagdorn M, Maillot PB and Zatsepin S (2009) Drainage beneath ice sheets: groundwater-channel coupling, and the origin of esker systems from former ice sheets. Quat. Sci. Rev., 28(7-8), 621-638

Brinkerhoff DJ, Meyer CR, Bueler E, Truffer M and Bartholomaus TC (2016) Inversion of a glacier hydrology model. Ann. Glaciol., 57, $1-12$

Budd WF, Keage PL and Blundy NA (1979) Empirical studies of ice sliding. J. Glaciol., 23, 157-170

Carter SP, Fricker HA and Siegfried MR (2017) Antarctic subglacial lakes drain through sediment-floored canals: theory and model testing on real and idealized domains. Cryosphere, 11(1), 381-405

Catania G and Paola C (2001) Braiding under glass. Geology, 29(3), 259

Christianson $\mathrm{K}$ and 7 others (2014) Dilatant till facilitates ice-stream flow in northeast Greenland. Earth Planet. Sci. Lett., 401, 57-69 
Clarke GKC (2005) Subglacial processes. Annu. Rev. Earth Planet. Sci., 33, 247-276

Creyts TT and Clarke GKC (2010) Hydraulics of subglacial supercooling: theory and simulations for clear water flows. J. Geophys. Res., 115(F3)

Creyts TT and Schoof CG (2009) Drainage through subglacial water sheets. J. Geophys. Res. Earth Surf., 114(F4)

Cundall PA and Strack ODL (1979) A discrete numerical model for granular assemblies. Géotechnique, 29, 47-65

Damsgaard A and 5 others (2013) Discrete element modeling of subglacial sediment deformation. J. Geophys. Res. Earth Surf., 118, 2230-2242

Damsgaard A and 5 others (2015) A new methodology to simulate subglacial deformation of water-saturated granular material. Cryosphere, 9, 2183-2200

Damsgaard A and 6 others (2016) Ice flow dynamics forced by water pressure variations in subglacial granular beds. Geophys. Res. Lett., 43

Davy P and Lague D (2009) Fluvial erosion/transport equation of landscape evolution models revisited. J. Geophys. Res., 114(F3)

de Fleurian B and 6 others (2014) A double continuum hydrological model for glacier applications. Cryosphere, 8(1), 137-153

Dow CF, Werder MA, Nowicki S and Walker RT (2016) Modeling Antarctic subglacial lake filling and drainage cycles. Cryosphere, 10(4), 1381-1393

Drews R and 9 others (2017) Actively evolving subglacial conduits and eskers initiate ice shelf channels at an Antarctic grounding line. Nat. Commun., 8, 15228

Einstein HA (1950) The bed-load function for sediment transportation in open channel flows, vol. 1026. U.S. Department of Agricure, Washington, DC

Elsworth CW and Suckale J (2016) Rapid ice flow rearrangement induced by subglacial drainage in West Antarctica. Geophys. Res. Lett., 43(22), 11697-11707

Engelhardt H and Kamb B (1997) Basal hydraulic system of a West Antarctic ice stream: Constraints from borehole observations. J. Glaciol., 43(144), 207-230

Engelhardt H, Humphrey N, Kamb B and Fahnestock M (1990) Physical conditions at the base of a fast moving Antarctic ice stream. Science, 248(4951), 57-59

Ergenzinger C, Seifried R and Eberhard P (2011) A discrete element model to describe failure of strong rock in uniaxial compression. Granul. Matter, 13, 341-364

Flowers GE (2015) Modelling water flow under glaciers and ice sheets. Proc. R. Soc. Lond. A, R. Soc., 471, 20140907

Fowler A and Walder J (1993) Creep closure of channels in deforming subglacial till. Proc. R. Soc. Lond. A, R. Soc., 441, 17-31

Fowler AC (1987) Sliding with cavity formation. J. Glaciol., 33(115), 255-267

Fricker HA, Siegfried MR, Carter SP and Scambos TA (2016) A decade of progress in observing and modelling Antarctic subglacial water systems. Phil. Trans. R. Soc. A, 374(2059), 20140294

GDR-MiDi (2004) On dense granular flows. Euro. Phys. J. E, 14, 341-365

Gillet-Chaulet F and 6 others (2016) Assimilation of surface velocities acquired between 1996 and 2010 to constrain the form of the basal friction law under Pine Island Glacier. Geophys. Res. Lett., 43(19), 10311-10321

Gimbert F, Tsai VC, Amundson JM, Bartholomaus TC and Walter JI (2016) Subseasonal changes observed in subglacial channel pressure, size, and sediment transport. Geophys. Res. Lett., 43 (8), 3786-3794

Goldberg DN, Schoof C and Sergienko OV (2014) Stick-slip motion of an Antarctic Ice Stream: The effects of viscoelasticity. J. Geophys. Res. Earth Surf., 119(7), 1564-1580

Goren L, Aharonov E, Sparks D and Toussaint R (2011) The mechanical coupling of fluid-filled granular material under shear. Pure Appl. Geophys., 168(12), 2289-2323
Greenwood SL, Clason CC, Nyberg J, Jakobsson M and Holmlund P (2016) The Bothnian Sea ice stream: early Holocene retreat dynamics of the southcentral Fennoscandian Ice Sheet. Boreas, 46(2), 346-362

Henderson FM (1966) Open Channel Flow. MacMillan, New York

Hewitt IJ (2011) Modelling distributed and channelized subglacial drainage: the spacing of channels. J. Glaciol., 57(202), 302-314

Hewitt IJ (2013) Seasonal changes in ice sheet motion due to melt water lubrication. Earth Planet. Sci. Lett., 371-372, 16-25

Hooke RLeB (1984) On the role of mechanical energy in maintaining subglacial water conduits at atmospheric pressure. J. Glaciol., 30, $180-187$

Hooke RLeB, Hanson B, Iverson NR, Jansson P and Fischer UH (1997) Rheology of till beneath Storglaciären, Sweden. J. Glaciol., 43(143), 172-179

Hooyer TS and Iverson NR (2000) Diffusive mixing between shearing granular layers: constraints on bed deformation from till contacts. J. Glaciol., 46(155), 641-651

Horgan HJ and 7 others (2013) Estuaries beneath ice sheets. Geology, 41(11), 1159-1162

Houssais M and Jerolmack DJ (2017) Toward a unifying constitutive relation for sediment transport across environments. Geomorphology, 277, 251-264

Houssais M and Lajeunesse E (2012) Bedload transport of a bimodal sediment bed. J. Geophys. Res.: Earth Surf., 117(F4), F04015

Houssais M, Ortiz CP, Durian DJ and Jerolmack DJ (2015) Onset of sediment transport is a continuous transition driven by fluid shear and granular creep. Nat. Commun., 6

Houssais M, Ortiz CP, Durian DJ and Jerolmack DJ (2016) Rheology of sediment transported by a laminar flow. Phys. Rev. E, 94(6)

Hubbard B and Nienow P (1997) Alpine subglacial hydrology. Quat. Sci. Rev., 16, 939-955

Iken A (1981) The effect of the subglacial water pressure on the sliding velocity of a glacier in an idealized numerical model. J. Glaciol., 27(97), 407-421

Iverson NR and Iverson RM (2001) Distributed shear of subglacial till due to Coulomb slip. J. Glaciol., 47(158), 481-488

Iverson NR, Hooyer TS and Baker RW (1998) Ring-shear studies of till deformation: Coulomb-plastic behavior and distributed strain in glacier beds. J. Glaciol., 148, 634-642

Iverson NR and 7 others (2007) Soft-bed experiments beneath Engabreen, Norway: regelation infiltration, basal slip and bed deformation. J. Glaciol., 53(182), 323-340

Jenkins A (2011) Convection-Driven Melting near the Grounding Lines of Ice Shelves and Tidewater Glaciers. J. Phys. Oceanogr., 41(12), 2279-2294

Jørgensen F and Sandersen PBE (2006) Buried and open tunnel valleys in Denmark-erosion beneath multiple ice sheets. Quat. Sci. Rev., 25(11-12), 1339-1363

Kamb B (1991) Rheological nonlinearity and flow instability in the deforming bed mechanism of ice stream motion. J. Geophys. Res., 96(B10), 16585-16595

Kamb B (2001) The West Antarctic Ice Sheet: Behavior and Environment, in Alley RB and Bindshadler RA (eds) Basal Zone of the West Antarctic Ice Streams and its Role in Lubrication of Their Rapid Motion, pp. 157-199. American Geophysical Union, Washington DC

Kavanaugh JL and Clarke GKC (2006) Discrimination of the flow law for subglacial sediment using in situ measurements and an interpretation model. J. Geophys. Res. Earth Surf., 111(F1)

Kehew AE, Piotrowski JA and Jørgensen F (2012) Tunnel valleys: Concepts and controversies - A review. Earth-Sci. Rev., 113, 33-58

King EC, Hindmarsh RCA and Stokes CR (2009) Formation of megascale glacial lineations observed beneath a West Antarctic ice stream. Nat. Geosci., 2(8), 585-588

Kingslake J and Ng F (2013) Modelling the coupling of flood discharge with glacier flow during jkulhlaups. Ann. Glaciol., 54 (63), 25-31 
Kruggel-Emden H, Sturm M, Wirtz S and Scherer V (2008) Selection of an appropriate time integration scheme for the discrete element method (DEM). Comput Chem. Eng., 32(10), 2263-2279

Kudrolli A and Clotet X (2016) Evolution of porosity and channelization of an erosive medium driven by fluid flow. Phys. Rev. Lett., 117, 028001

Kulessa B and 10 others (2017) Seismic evidence for complex sedimentary control of Greenland Ice Sheet flow. Sci. Adv., 3(8), e1603071

Kyrke-Smith TM, Katz RF and Fowler AC (2015) Subglacial hydrology as a control on emergence, scale, and spacing of ice streams. J. Geophys. Res. Earth Surf., 120, 1501-1514

Lajeunesse E, Malverti L and Charru F (2010) Bed-load transport in turbulent flow at the grain scale: experiments and modeling. J. Geophys. Res., 115(F4)

Le Brocq AM and 10 others, 2013. Evidence from ice shelves for channelized meltwater flow beneath the Antarctic Ice Sheet, Nat. Geosci., 6(11), 945-948

Lesemann J-E, Piotrowski JA and Wysota W (2010) "Glacial curvilineations": new glacial landforms produced by longitudinal vortices in subglacial meltwater flows. Geomorphology, 120(3-4), 153-161

Lesemann J-E, Piotrowski JA and Wysota W (2014) Genesis of the "glacial curvilineation" landscape by meltwater processes under the former Scandinavian Ice Sheet, Poland. Sediment. Geol., 312, 1-18

Lliboutry L (1968) General theory of subglacial cavitation and sliding of temperate glaciers. J. Claciol., 7, 21-58

Luding S (2008) Introduction to DEMs: basic of contact force models and how to perform the micro-macro transition to continuum theory. Euro. J. Environ. Civil Eng., 12(7-8), 785-826

Mahadevan A, Orpe AV, Kudrolli A and Mahadevan L (2012) Flowinduced channelization in a porous medium. Eur. Phys. Lett., 98 (5), 58003

Marsh OJ and 6 others (2016) High basal melting forming a channel at the grounding line of Ross Ice Shelf, Antarctica. Geophys. Res. Lett., 43(1), 250-255

McNamara S, Flekkøy EG and Måløy KJ (2000) Grains and gas flow: Molecular dynamics with hydrodynamic interactions. Phys. Rev. E, 61, 4054-4059

Métivier F, Lajeunesse E and Devauchelle O (2017) Laboratory rivers: Lacey's law, threshold theory, and channel stability. Earth Surf. Dyn., 5(1), 187-198

Meyer-Peter E and Müller R (1948) Formulas for bed-load transport. Int. Assoc. for Hydraul. Res., Stockholm

Minchew B and 7 others (2016) Plastic bed beneath Hofsjökull Ice Cap, central Iceland, and the sensitivity of ice flow to surface meltwater flux. J. Glaciol., 62, 147-158

Mitchell JK and Soga K (2005) Fundamentals of soil behavior. Wiley, New York

Moore PL and Iverson NR (2002) Slow episodic shear of granular materials regulated by dilatant strengthening. Geology, 30(9), 843-846

Nedderman RM (1992) Statics and kinematics of granular materials. Cambridge University Press, Cambridge

Ng FSL (2000a) Canals under sediment-based ice sheets. Ann. Glaciol., 30, 146-152

Ng FSL (2000b) Coupled ice-till deformation near subglacial channels and cavities. J. Glaciol., 46(155), 580-598

Nye JF (1976) Water flow in glaciers: jökulhlaups, tunnels and veins. J. Glaciol., 17, 181-207

Obermayr M, Dressler K, Vrettos C and Eberhard P (2013) A bondedparticle model for cemented sand. Comput. Geotech., 49, 299-313

Parker G (1978) Self-formed straight rivers with equilibrium banks and mobile bed. Part 1. The sand-silt river. J. Fluid Mech., 89(1), 109

Perol T and Rice JR (2015) Shear heating and weakening of the margins of West Antarctic ice streams. Ceophys. Res. Lett., 42(9), 3406-3413
Perol T, Rice JR, Platt JD and Suckale J (2015) Subglacial hydrology and ice stream margin locations. J. Geophys. Res. Earth Surf., 120, 1352-1368

Piotrowski JA (1999) Channelized subglacial drainage under softbedded ice sheets: evidence from small $\mathrm{N}$-channels in Central European Lowland. Geol. Q., 43(2), 153-162

Piotrowski JA, Geletneky J and Vater R (1999) Soft-bedded subglacial meltwater channel from the Welzow-Süd open-cast lignite mine, Lower Lusatia, eastern Germany. Boreas, 28(3), 363-374

Piotrowski JA, Larsen NK and Junge FW (2004) Reflections on soft subglacial beds as a mosaic of deforming and stable spots. Quat. Sci. Rev., 23(9), 993-1000

Piotrowski JA, Hermanowski P and Piechota AM (2009) Meltwater discharge through the subglacial bed and its land-forming consequences from numerical experiments in the Polish lowland during the last glaciation. Earth Surf. Process. Landforms, 34(4), 481-492

Pons A, Amon A, Darnige T, Crassous J and Clément E (2015) Mechanical fluctuations suppress the threshold soft-glassy solids: The secular drift scenario. Phys. Rev. E, 92(2)

Radjaï F and Dubois F (2011) Discrete-element modeling of granular materials. Wiley-Iste, London, UK

Raymond CF (2000) Energy balance of ice streams. J. Glaciol., 46 (155), 665-674

Rempel AW (2009) Effective stress profiles and seepage flows beneath glaciers and ice sheets. J. Glaciol., 55(191), 431-443

Rosier SHR, Gudmundsson GH and Green JAM (2015) Temporal variations in the flow of a large Antarctic ice-stream controlled by tidally induced changes in the subglacial water system. Cryosphere Discuss., 9, 2397-2429

Röthlisberger H (1972) Water pressure in intra-and subglacial channels. J. Glaciol., 11(62), 177-203

Schellart WP (2000) Shear test results for cohesion and friction coefficients for different granular materials: scaling implications for their usage in analogue modelling. Tectonophysics, 324(1), 1-16

Schofield AN and Wroth P (1968) Critical state soil mechanics. McGraw-Hill, London

Schoof C (2010) Ice-sheet acceleration driven by melt supply variability. Nature, 468(7325), 803-806

Schoof C, Rada CA, Wilson NJ, Flowers GE and Haseloff M (2014) Oscillatory subglacial drainage in the absence of surface melt. Cryosphere, 7(6), 959-976

Schroeder DM, Blankenship DD and Young DA (2013) Evidence for a water system transition beneath Thwaites Glacier, West Antarctica. Proc. Natl. Acad. Sci. USA, 110(30), 12225-12228

Shields IA (1936) Anwendung der Aehnlichkeitsmechanik und der Turbulenzforschung auf die Geschiebebewegung. Mitt. Preuss Ver.-Anst, 26

Shoemaker EM (1986) Subglacial hydrology for an ice sheet resting on a deformable aquifer. J. Glaciol., 32(110), 20-30

Shreve RL (1972) Movement of water in glaciers. J. Glaciol., 11(62), 205-214

Simkins LM and 8 others (2017) Anatomy of a meltwater drainage system beneath the ancestral East Antarctic ice sheet. Nat. Geosci. 10, 691-697

Stevens LA and 7 others (2015) Greenland supraglacial lake drainages triggered by hydrologically induced basal slip. Nature, 522(7554), 73-76

Stock JD and Montgomery DR (1999) Geologic constraints on bedrock river incision using the stream power law. J. Geophys. Res. Solid Earth, 104(B3), 4983-4993

Stokes CR and Clark CD (2001) Palaeo-ice streams. Quat. Sci. Rev., 20(13), 1437-1457

Suckale J, Platt JD, Perol T and Rice JR (2014) Deformation-induced melting in the margins of the West Antarctic ice streams. J. Geophys. Res. Earth Surf., 119(5), 1004-1025

Swift DA, Nienow PW, Spedding N and Hoey TB (2002) Geomorphic implications of subglacial drainage configuration: rates of basal sediment evacuation controlled by seasonal drainage system evolution. Sediment. Geol., 149, 5-19 
Terzaghi K (1943) Theoretical soil mechanics. Wiley. London, UK

Terzaghi K, Peck RB and Mesri G (1996) Soil mechanics in engineering practice. John Wiley \& Sons, London, UK

Thompson J, Simons M and Tsai VC (2014) Modeling the elastic transmission of tidal stresses to great distances inland in channelized ice streams. Cryosphere, 8(6), 2007-2029

Tulaczyk S (2006) Scale independence of till rheology. J. Glaciol., 52 (178), 377-380

Tulaczyk S, Kamb WB and Engelhardt HF (2000a) Basal mechanics of ice stream B, West Antarctica I. Till mechanics. J. Geophys. Res., 105(B1), 463-481

Tulaczyk S, Kamb WB and Engelhardt HF (2000b) Basal mechanics of ice stream B, West Antarctica II. Undrained plastic-bed model. J. Geophys. Res., 105(B1), 483-494

Tylmann K, Piotrowski JA and Wysota W (2013) The ice/bed interface mosaic: deforming spots intervening with stable areas under the fringe of the Scandinavian Ice Sheet at Sampława, Poland. Boreas, 42(2), 428-441

Utter B, Behringer RP (2004) Self-diffusion in dense granular shear flows. Phys. Rev. E, 69(3)

van der Wel N, Christoffersen P and Bougamont M (2013) The influence of subglacial hydrology on the flow of Kamb Ice Stream, West Antarctica, J. Geophys. Res. Earth Surf., 118(1), 97-110

Walder JS and Fowler A (1994) Channelized subglacial drainage over a deformable bed. J. Glaciol., 40(134)

Walder JS, Iverson RM, Godt JW, Logan M and Solovitz SA (2015) Controls on the breach geometry and flood hydrograph during overtopping of noncohesive earthen dams. Water Resour. Res., 51, 6701-6724

Walker RT, Christianson K, Parizek BR, Anandakrishnan S and Alley RB (2012) A viscoelastic flowline model applied to tidal forcing of Bindschadler Ice Stream, West Antarctica. Earth Planet. Sci. Lett., 319, 128-132

Weertman J (1957) On the sliding of glaciers. J. Glaciol., 3(21), 33-38

Werder MA, Hewitt IJ, Schoof CG and Flowers GE (2013) Modeling channelized and distributed subglacial drainage in two dimensions. J. Geophys. Res. Earth Surf., 118(4), 2140-2158
Whipple KX and Tucker GE (1999) Dynamics of the stream-power river incision model: implications for height limits of mountain ranges, landscape response timescales, and research needs. J. Geophys. Res. Solid Earth, 104(B8), 17661-17674

Wilcock PR (1998) Two-fraction model of initial sediment motion in gravel-bed rivers. Science, 280(5362), 410-412

Winberry JP, Anandakrishnan S and Alley RB (2009) Seismic observations of transient subglacial water-flow beneath MacAyeal Ice Stream, West Antarctica. Geophys. Res. Lett., 36(11)

$\mathrm{Xu} B \mathrm{H}$ and $\mathrm{Yu} A B$ (1997) Numerical simulation of the gas-solid flow in a fluidized bed by combining discrete particle method with computational fluid dynamics. Chem. Eng. Sci., 52(16), 27852809

Xu Y, Rignot E, Menemenlis D and Koppes M (2012) Numerical experiments on subaqueous melting of Greenland tidewater glaciers in response to ocean warming and enhanced subglacial discharge. Ann. Glaciol., 53(60), 229-234

Zhang Y and Campbell CS (1992) The interface between fluid-like and solid-like behavior in two-dimensional granular flows. J. Fluid Mech., 237541

Zhou ZY, Kuang SB, Chu KW and Yu AB (2010) Discrete particle simulation of particle-fluid flow: model formulations and their applicability. J. Fluid Mech., 661, 482-510

Zhu HP, Zhou ZY, Yang RY and Yu AB (2007) Discrete particle simulation of particulate systems: Theoretical developments. Chem. Eng. Sci., 62, 3378-3396

\section{APPENDIX A. SOURCE CODE AVAILABILITY}

The source code for the grain-fluid model is available at https://github.com/anders-dc/sphere, where the script channel-wet.py can be used as a template for model runs. An example implementation of the subglacial hydrology model built on channelization dynamics is available from https://github.com/anders-dc/granular-channel-hydro/blob/ master/1d-channel.py.

MS received 19 June 2017 and accepted in revised form 9 October and 10 October 2017; first published online 27 November 2017 